\title{
Antibody response and therapy in COVID-19 patients: what can be learned for vaccine development?
}

\author{
Ligong Lu ${ }^{1 *}$, Hui Zhang ${ }^{2}$, Meixiao Zhan ${ }^{1}$, Jun Jiang ${ }^{3}$, Hua Yin ${ }^{1}$, Danielle J. Dauphars ${ }^{4}$, \\ Shi-You $\mathrm{Li}^{3}$, Yong $\mathrm{Li}^{1}$ \& You-Wen $\mathrm{He}^{4 *}$ \\ ${ }^{1}$ Zhuhai Interventional Medical Center, Zhuhai Precision Medical Center, Zhuhai People's Hospital, Zhuhai Hospital Affiliated with Jinan \\ University, Zhuhai 519000, China; \\ ${ }^{2}$ First Affiliated Hospital, China Medical University, Shenyang 110001, China; \\ ${ }^{3}$ tricision Biotherapeutic Inc., Zhuhai 519041, China; \\ ${ }^{4}$ Department of Immunology, Duke University Medical University Medical Center, Durham, NC 27710, USA
}

Received August 6, 2020; accepted November 27, 2020; published online December 1, 2020

\begin{abstract}
The newly emerged severe acute respiratory syndrome coronavirus 2 (SARS-CoV-2) has infected millions of people and caused tremendous morbidity and mortality worldwide. Effective treatment for coronavirus disease 2019 (COVID-19) due to SARS$\mathrm{CoV}-2$ infection is lacking, and different therapeutic strategies are under testing. Host humoral and cellular immunity to SARS$\mathrm{CoV}-2$ infection is a critical determinant for patients' outcomes. SARS-CoV-2 infection results in seroconversion and production of anti-SARS-CoV-2 antibodies. The antibodies may suppress viral replication through neutralization but might also participate in COVID-19 pathogenesis through a process termed antibody-dependent enhancement. Rapid progress has been made in the research of antibody response and therapy in COVID-19 patients, including characterization of the clinical features of antibody responses in different populations infected by SARS-CoV-2, treatment of COVID-19 patients with convalescent plasma and intravenous immunoglobin products, isolation and characterization of a large panel of monoclonal neutralizing antibodies and early clinical testing, as well as clinical results from several COVID-19 vaccine candidates. In this review, we summarize the recent progress and discuss the implications of these findings in vaccine development.
\end{abstract}

COVID-19, seroconversion, neutralizing antibody, spike protein, SARS-CoV-2, convalescent plasma, vaccine

Citation: $\quad$ Lu, L., Zhang, H., Zhan, M., Jiang, J., Yin, H., Dauphars, D.J., Li, S.Y., Li, Y., and He, Y.W. (2020). Antibody response and therapy in COVID-19 patients: what can be learned for vaccine development?. Sci China Life Sci 63, 1833-1849. https://doi.org/10.1007/s11427-020-1859-y

\section{Introduction}

The newly emerged severe acute respiratory syndrome coronavirus 2 (SARS-CoV-2) has infected $>60$ million people to cause coronavirus disease 2019 (COVID-19) and led to $>1.4$ million deaths worldwide as of November 25, 2020 (Johns Hopkins University, 2020). SARS-CoV-2 belongs to the $\beta$ subgroup of the Coronaviridae family consisting of four

*Corresponding authors (You-Wen He, email: youwen.he@duke.edu; Ligong Lu, email: luligong1969@126.com) genera $\alpha, \beta, \gamma$ and $\delta$ (Lu et al., 2020c; Zhou et al., 2020b). The $\beta$ subgroup of the Coronaviridae family also includes two other highly pathogenic viruses, SARS-CoV and middle eastern respiratory syndrome (MERS-CoV) that have caused outbreaks in 2002-2003 and 2013-present, respectively (Tse et al., 2020). The SARS-CoV-2 RNA genome encodes four conserved structural proteins, spike (S), envelope (E), membrane $(\mathrm{M})$, and nucleocapsid $(\mathrm{N})$ as well as at least six accessory proteins (3a, 6, 7a, 7b, 8 and 10) (Kim et al., 2020). SARS-CoV-2 infects host cells through its S protein, which consists of the $\mathrm{S} 1$ subunit, $\mathrm{S} 2$ subunit, transmembrane, and 
cytoplasmic domains. The $\mathrm{S} 1$ subunit is further divided into $\mathrm{N}$-terminal domain (NTD), receptor-binding domain (RBD), subdomain 1 (SD1), and subdomain 2 (SD2). The RBD in the S1 subunit of SARS-CoV-2 binds to cellular receptor angiotensin-converting enzyme 2 (ACE2) (Hoffmann et al., 2020; Sungnak et al., 2020; Wang et al., 2020d; Yan et al., 2020) or CD147 (Wang et al., 2020b) and mediates virus entry. Upon RNA genome deposit into the cytoplasm, SARS-CoV-2 goes through cycles of intracellular replication and is released by exocytosis to infect other host cells (Hartenian et al., 2020).

The high morbidity and mortality of COVID-19 patients poses a tremendous health challenge and calls for urgent development of effective prevention and treatment strategies. The major pathology caused by SARS-CoV-2 infection is pneumonia. Severe and critically ill COVID-19 patients also have other organ damage (Robba et al., 2020). Moribund COVID-19 patients go through three distinct stages: initiation, amplification, and consummation ( $\mathrm{Lu}$ et al., 2020b). The initiation stage is characterized by rapid viral replication and early induction of predominant chemokines. In the absence of effective viral suppression by host humoral and cellular immunity, patients enter the amplification stage in which both rampant production of more inflammatory mediators and massive recruitment of inflammatory cells to amplify immunopathological processes occur. Subsequently, COVID-19 patients succumb due to continuous increases of inflammatory mediators and widespread organ damage in the consummation stage (Lu et al., 2020b). Antibody-mediated humoral immune responses to SARS-CoV-2 infection play essential roles in COVID-19 disease development. Upon infection, host B lymphocytes recognizing SARS-CoV-2specific antigens are activated, and antibody production is initiated. Seroconversion of IgM, IgA, and IgG and the appearance of neutralizing antibodies to SARS-CoV-2 suppress viral replication. In the 9 months since the COVID-19 pandemic began, rapid progress has been made in the characterization of antibody responses including the dynamics and properties of anti-SARS-CoV-2 antibodies in infected populations. Furthermore, results from clinical studies using passive antibody treatment of COVID-19 patients with convalescent plasma and intravenous immunoglobulins (IVIG) have been reported. A large panel of neutralizing monoclonal antibodies have been isolated and some have been tested clinically. Importantly, clinical efficacy data from several vaccine trials has been reported. In this review, we summarize recent results on antibody response and therapy in COVID-19 patients. We further discuss the clinical significance of these results in the context of vaccine development.

\section{Humoral responses to SARS-CoV-2 infection in COVID-19 patients}

The development of antibodies to SARS-CoV-2 has been assessed in COVID-19 patients at different disease stages and severities. Specific IgA, IgM, IgG, or total antibodies to SARS-CoV-2 antigens, including full length $\mathrm{S}$ protein, RBD, $\mathrm{E}$, and $\mathrm{N}$ proteins, were assessed for binding activities in peripheral blood of a total of 4,261 patients (Table 1) (Guo et al., 2020; Juno et al., 2020; Li et al., 2020a; Long et al., 2020a; Lou et al., 2020; Lynch et al., 2020; Ni et al., 2020; Prevost et al., 2020; Ren et al., 2020; To et al., 2020b; Wajnberg et al., 2020; Wang et al., 2020e; Yu et al., 2020a; Zhang et al., 2020c; Zhao et al., 2020). Additional studies were also analyzed and presented in a systemic review (Deeks et al., 2020). Several major features appeared from these studies.

First, most of the COVID-19 patients developed one or

Table 1 Summary of antibody responses in COVID-19 patients ${ }^{\text {a) }}$

\begin{tabular}{|c|c|c|c|c|c|c|c|c|c|c|}
\hline \multirow{2}{*}{ Studies } & \multirow{2}{*}{ Pts\# } & \multirow{2}{*}{$\begin{array}{l}\text { Period } \\
\text { (days) }\end{array}$} & \multicolumn{2}{|c|}{ Anti-viral Ag (\%) } & \multicolumn{2}{|c|}{ Anti-spike (\%) } & \multicolumn{2}{|c|}{ Anti-N protein $(\%)$} & \multirow{2}{*}{$\begin{array}{l}\text { Titer/severity } \\
\text { correlation }\end{array}$} & \multirow{2}{*}{ References } \\
\hline & & & $\operatorname{IgM}$ & $\operatorname{IgG}$ & $\operatorname{IgM}$ & $\mathrm{IgG}$ & IgM & $\operatorname{IgG}$ & & \\
\hline 1 & 16 & $\geq 10$ & & & 94 & 100 & 88 & 94 & & (To et al., 2020b) \\
\hline 2 & 112 & $\geq 4$ & $53(\mathrm{~N} / \mathrm{E})$ & $93(\mathrm{~N} / \mathrm{E})$ & & & & & & (Zhang et al., 2020c) \\
\hline 3 & 173 & $\geq 0$ & $93^{*}$ & $93^{*}(?)$ & 83 & & 65 & & + & (Zhao et al., 2020) \\
\hline 4 & 285 & $\geq 3$ & $94(\mathrm{~N} / \mathrm{S})$ & $100(\mathrm{~N} / \mathrm{S})$ & & & & & & (Long et al., 2020a) \\
\hline 5 & 98 & $\geq 2$ & & & 78 & 100 & & & & (Prevost et al., 2020) \\
\hline 6 & 30,082 & $\geq 3$ & & & & 95 & & & & (Wajnberg et al., 2020) \\
\hline 7 & 94 & $3-28$ & & & 60 & 49 & & & + & (Lynch et al., 2020) \\
\hline 8 & 140 & $\geq 1$ & & & & & 85 & 78 & & (Guo et al., 2020) \\
\hline 9 & 80 & $\geq 5$ & & & 100 & & & 97 & & (Lou et al., 2020) \\
\hline 10 & 1,850 & $\geq 0$ & $97^{*}$ & $97^{*}(\mathrm{~N} / \mathrm{S})$ & & & & & + & (Li et al., 2020a) \\
\hline 11 & 70 & $\geq 10$ & $100^{*}$ & $100^{*}$ (Virus) & & & & & + & (Wang et al., 2020e) \\
\hline
\end{tabular}

a) Pts: patents. Period: days refer to the time that samples were taken since onset of symptom. *: SARS-CoV-2 antigens were either mixed or not specified in the studies. (N/E): letters in parenthesis indicate specific antigens used in the test; N, nucleocapsid protein; E, E antigen; S, Spike protein. 
more antigen-specific antibodies to SARS-CoV-2 during the course of the disease. The rates of antibody positivity ranged from $53 \%$ to $100 \%$ and were clearly time-dependent (Table $1)$. Pooled results showed that specific antibodies were detected in $<30.1 \%$ of patients during the first week after disease onset (Deeks et al., 2020). The positive rates rapidly rose to $72.2 \%$ and $91.4 \%$ during the second and third weeks after the onset of disease, respectively, and reached $96.0 \%$ by the end of the fifth week (Deeks et al., 2020). Thus, regardless of patient characteristics (age, sex, co-morbidities, and treatments), SARS-CoV-2 is a strongly immunogenic virus that can induce antigen-specific antibody production in most infected patients.

Second, the patterns of antibody seroconversion varied. Three types of seroconversion of antigen-specific $\operatorname{IgM}$ and IgG were observed: IgM seroconverted earlier than IgG, IgG seroconverted earlier than IgM, and IgM and IgG seroconverted synchronously (Long et al., 2020a). The pattern of seroconversion of IgG prior to IgM may be caused by some level of cross-reactivity between SARS-CoV-2 and other viruses previously infecting the hosts and suggest activation of memory B cell populations. This pattern of response may be clinically significant in COVID-19 pathogenesis (see discussion below). Nevertheless, the pattern of IgM seroconversion before IgG was most commonly observed in COVID-19 patients (Guo et al., 2020; Lou et al., 2020; Lynch et al., 2020; Zhang et al., 2020c; Zhao et al., 2020). The median seroconversion time for $\operatorname{IgM}$ and $\operatorname{IgG}$ were 5-11 and 10-15 days after disease onset, respectively (Guo et al., 2020; Lou et al., 2020; Lynch et al., 2020; Zhang et al., 2020c; Zhao et al., 2020). The levels of IgM reached the peak earlier than IgG and declined after one month. In contrast, the levels of IgG elevated later but lasted longer (Zhang et al., 2020c). However, specific IgM antibody response was delayed in COVID-19 patients with severe progression (Shen et al., 2020b). SARS-CoV-2-specific blood IgA had a median seroconversion time at 2-5 days after symptom onset (Guo et al., 2020; Yu et al., 2020a). Secretory IgA was also measured in milk samples from SARS-CoV-2infected donors and $80 \%$ of the samples exhibited both blood and secretory IgA reactivity, indicating efficient induction of secretory IgA (Fox et al., 2020).

Third, the levels of anti-SARS-CoV-2 antibodies are strongly correlated with COVID-19 disease severity (Figure 1A). In a cohort of 173 patients, the antibody titers in critically ill COVID-19 patients were significantly higher than those in non-critically ill patients and were independent factors for disease severity classification (Zhao et al., 2020). Critically ill COVID-19 patients had much higher IgM and/ or IgG titers than mild cases (Kutsuna et al., 2020; Liu et al., 2020c; Lynch et al., 2020). Higher neutralizing antibody titers were also associated with worse clinical classifications (Wang et al., 2020e). Furthermore, anti-SARS-CoV-2 (S,
RBD, and N) antibodies in severe/critically ill COVID-19 patients developed one week later than those in mild/moderate patients but were 1.5-fold higher (Li et al., 2020a) (Figure 1A). These results raise the question of whether the increased levels of anti-SARS-CoV-2 antibodies play a pathological role in COVID-19 pathogenesis (Lee et al., 2020b). Previous studies suggest that anti-SARS-CoV antibodies may mediate an antibody-dependent enhancement (ADE) effect (Peiris et al., 2003; Liu et al., 2019; Arvin et al., 2020). If anti-SARS-CoV2 antibodies indeed contribute to COVID-19 pathogenesis, it will be critical to determine which class of antibodies (IgA, $\operatorname{IgM}, \operatorname{IgG}$ ) and what antigen specificities are involved in the process.

Fourth, antibody responses were different in adults and children (Pierce et al., 2020; Weisberg et al., 2020). COVID19 positive adults developed anti-S IgG, IgM and IgA classes as well as anti-N IgG antibody, while COVID-19 positive children predominantly developed anti-S but not anti-N IgG antibody (Weisberg et al., 2020). Children had reduced breadth of antigen-specific antibodies as well as neutralizing activity, indicating a reduced humoral response (Pierce et al., 2020; Weisberg et al., 2020). These observations may be related to antibody-mediated disease pathology in adult patients.

Fifth, anti-SARS-CoV-2 antibodies may not last long after COVID-19 recovery. Many studies have reported the decline of anti-SARS-CoV-2 antibodies in convalescent COVID-19 patients (Chen et al., 2020b; Harvala et al., 2020; Ibarrondo et al., 2020; Isho et al., 2020; Iyer et al., 2020; Kutsuna et al., 2020; Ma et al., 2020; Terpos et al., 2020). Ma and colleagues showed that anti-RBD antibodies in most COVID-19 patients reduced significantly within 100 days after discharge and they further predicted that the anti-SARS-CoV-2 antibodies would disappear in 9 months (Ma et al., 2020). Within the three classes of anti-SARS-CoV-2 antibodies, IgA and IgM have much shorter lives than antigen-specific IgG (Isho et al., 2020; Iyer et al., 2020). The seroreversion time (in contrast to seroconversion) for antigen-specific IgA and IgM was 71 and 49 days, respectively, while IgG decayed slowly over 3-4 months (Isho et al., 2020; Iyer et al., 2020). Interestingly, a small group of COVID-19 patients, who recovered rapidly from their symptoms, had stable or increasing antibody levels in the same time frame despite similar initial antibody levels (Chen et al., 2020b). These patients had increased $\mathrm{T}$ helper cell activity and enriched somatic mutations in virus-specific memory B cell antibody genes. The above clinical reports suggest two important points. First, most of the recovered COVID-19 patients may still need vaccination to prevent reinfection after 6 months or more. Second, an effective vaccine needs to engage all arms (B cell, CD4 T and CD8 T cells) of the adaptive immune response using a three-pronged vaccine design strategy $(\mathrm{Lu}$ et al., 2020a). 
A

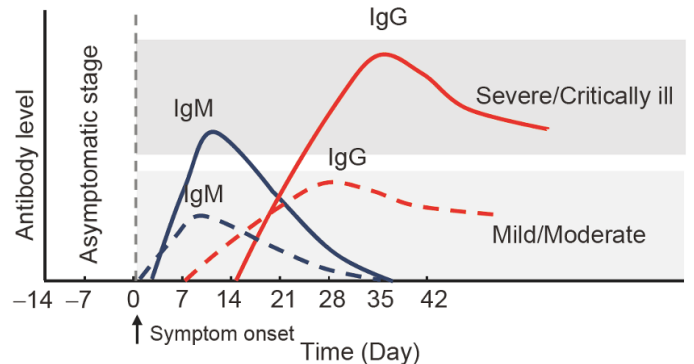

C mRNA-nanoparticle Adenovirus-vectored maccine
vaccine
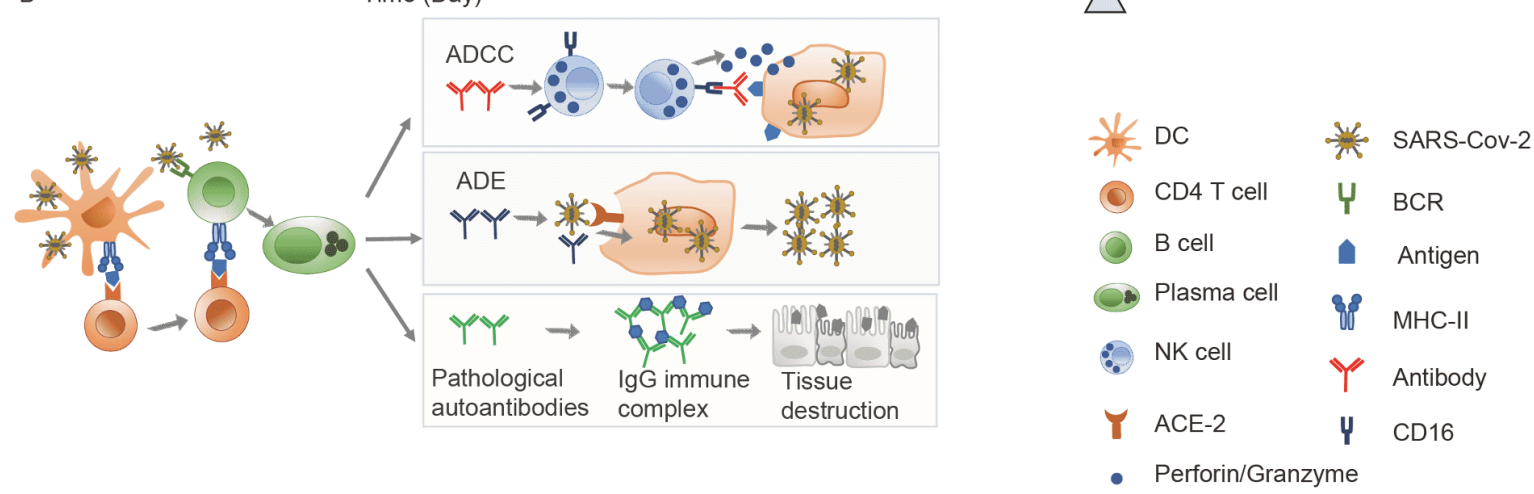

Figure 1 Antibody response and function in COVID-19 immunity and pathogenesis. A, Kinetics of antibody responses in mild/moderate and severe/ critically ill COVID-19 patients. Antibody responses were delayed but elevated in severe/critically ill patients. B, Multiple functions of antibodies in COVID19 patients including neutralization, mediating antibody-dependent cellular cytotoxicity (ADCC), ADE and autoimmunity. C, Assessment of COVID-19 vaccine-induced immunity and pathogenesis.

Although SARS-CoV-2 induces specific antibody responses in the majority of infected humans, specific populations demonstrated defective antibody production. Renal transplant patients under immunosuppressive treatment failed to mount anti-SARS-CoV-2 IgM and IgG for a prolonged time (Lynch et al., 2020; Xia et al., 2020b). Patients with chronic lymphocytic leukemia had delayed or completely absent production of anti-SARS-CoV-2 antibodies and impaired viral clearance (Avanzato et al., 2020; Favresse et al., 2020; Roeker et al., 2020; Ye et al., 2020b). Interestingly, the patients developed antibodies after suspension of immunosuppressive treatment (Lynch et al., 2020). These clinical manifestations indicate that immunosuppressed populations have defective humoral responses to SARS-CoV-2 infection.

\section{Humoral responses to SARS-CoV-2 infection in asymptomatic populations}

A large fraction of the SARS-CoV-2 infected population is asymptomatic. Anti-SARS-CoV-2-specific antibodies were assessed in viral RNA confirmed asymptomatic patients, healthcare workers, and the general population. By studying seroconversion in these populations, it was shown that asymptomatically infected human subjects develop antiSARS-CoV-2 antibodies with different kinetics compared to symptomatic COVID-19 patients. Furthermore, the ser- opositive prevalence in the general population is directly associated with local pandemic levels of SARS-CoV-2 infection. Out of 200 front-line maternity health workers in London hospitals, $5.0 \%$ were found to be seropositive without any symptoms (Bampoe et al., 2020), while there was a $2.96 \%$ seropositivity in 1,282 healthcare workers in Minnesota, USA (Thomas et al., 2020). A significant number of parturient women $(6.2 \%, 80 / 1,293)$ in Philadelphia possessed IgG and/or IgM SARS-CoV-2-specific antibodies (Flannery et al., 2020). It was also reported that 5.6\% (174/ 3,098 ) of blood donors had anti-SARS-CoV-2 IgG (Uyoga et al., 2020). The prevalence of SARS-CoV-2 antibodies in populations was clearly related to local epidemic levels. Seropositivity was only $0.99 \%$ among 904 healthy blood donors in the low-incidence COVID-19 area of Southeastern Italy (Fiore et al., 2020). In contrast, a striking 23\% seropositive rate was observed in 390 blood donors in the high COVID-19 Lodi Red Zone in Italy (Percivalle et al., 2020). In testing serum samples from 16,025 persons collected from March 23 to May 12 at 10 sites in the United States, it was found that the seropositive rates ranged from $1.0 \%$ in the San Francisco Bay area (collected April 23-27) to 6.9\% in New York City (Havers et al., 2020). When compared to the locally reported confirmed numbers of COVID-19 cases during the same period, these seropositive rates suggest many more SARS-CoV-2 infections occurred in these sites than the reported cases. In two other large-scale studies, 3.2\%-3.8\% of a total of 35,759 human subjects in Wuhan, China tested 
positive for anti-SARS-CoV-2 IgG or IgM (Ling et al., 2020; $\mathrm{Xu}$ et al., 2020). The positive rates suggest a 3-4 times higher infection rate than the officially reported case numbers. Thus, these studies unequivocally demonstrate that a large fraction of SARS-CoV-2-infected humans were asymptomatic. It should be noted that these studies were based on samples largely collected in the first 4 months of the COVID-19 pandemic. As the pandemic rapidly expands both in case numbers and regions, the seropositive rates will undoubtedly change with the infections to levels whereby even herd immunity may be temporarily possible (Fontanet and Cauchemez, 2020).

Humoral responses in SARS-CoV-2-infected asymptomatic individuals differed from those in the symptomatic group in several ways (Long et al., 2020b). They had a longer duration of viral shedding and lower virus-specific IgG levels in the acute phase. The asymptomatic individuals also had reduced IgG and neutralizing antibody levels during the early convalescent phase when compared to the symptomatic group. Furthermore, $40 \%$ of the asymptomatic individuals became seronegative, versus $12.9 \%$ in the symptomatic group during the follow-up time (Long et al., 2020b). These results suggest that asymptomatically infected humans have weak immune responses to SARS-CoV-2 infection and raise a critical issue of whether these individuals have protective immunity against a second infection. Together with recent studies demonstrating rapid decay of anti-SARS-CoV-2 antibodies in convalescent COVID-19 patients (Chen et al., 2020b; Ibarrondo et al., 2020; Isho et al., 2020; Iyer et al., 2020; Kutsuna et al., 2020; Ma et al., 2020; Terpos et al., 2020), it is clear that potent COVID-19 vaccines are needed to elicit long lasting immune protection in the general population.

\section{Structural and neutralizing properties of anti- SARS-CoV-2 antibodies in COVID-19 patients}

Characterization of structural and neutralizing properties of anti-SARS-CoV-2 antibodies in COVID-19 patients has provided insights into potential mechanisms of antibodymediated pathogenesis and virus-induced protective immunity. Antibody glycosylation is an important functional determinant for IgG. Serum IgG is highly fucosylated in healthy humans (de Haan et al., 2016). However, low fucosylation of anti-RhD IgG in pregnancy was observed as a predicting factor for hemolytic disease severity of the fetus and newborn (Kapur et al., 2014). Furthermore, non-fucosylated (afucosylated) IgG at its Fc-domain leads to enhanced antibody-dependent cellular cytotoxicity (ADCC) through increased Fc-receptor (Fc $\gamma$ RIIIa) binding and has been developed as antibody therapy (Shields et al., 2002; Ferrara et al., 2011; Pereira et al., 2018). Fucosylation in
anti-S protein specific IgG1 in COVID-19 patients was analyzed and afucosylation was found in these specific antibodies (Chakraborty et al., 2020; Larsen et al., 2020). Importantly, afucosylated anti-S protein IgG1 was significantly increased in critically ill COVID-19 patients compared to that in asymptomatic and mild cases (Larsen et al., 2020). Afucosylated $\mathrm{Fc}$ modification on $\mathrm{IgG}$ enhanced interactions with the activating Fc $\gamma$ receptor Fc $\gamma$ RIIIa and the IgG antibody-antigen immune complexes enhanced production of inflammatory cytokines by monocytes (Chakraborty et al., 2020). These findings suggest that afucosylated antigenspecific IgG may have double roles: one to promote killing of SARS-CoV-2-infected target cells through ADCC and the other to mediate the ADE effect that exacerbates COVID-19 pathogenesis (Figure 1).

In a study to dissect early evolution of the antibody responses in COVID-19 patients with different severities, robust IgA and IgM antibody responses were found in both survivors and non-survivors (Zohar et al., 2020). However, antigen-specific IgG with compromised Fc $\gamma$ receptor binding and $\mathrm{Fc}$ effector activity was found in non-survivors, suggesting defective humoral response that may be associated with worse disease outcome (Zohar et al., 2020)

The kinetics of neutralizing activities of anti-SARS-CoV-2 antibodies in COVID-19 patients were measured using pseudotyped particles or native virus (Harvala et al., 2020; Ni et al., 2020; Prevost et al., 2020; Wang et al., 2020e; Wu et al., 2020a). Neutralizing antibodies developed within 2 weeks after disease onset and neutralizing activities significantly decreased after symptom resolution (Prevost et al., 2020). Notably, one study showed that $40 \%$ of convalescent patients did not have any neutralizing activity (Prevost et al., 2020), suggesting that neutralizing antibodies are not absolutely required for infection resolution. As expected, significant correlations between neutralizing activities and anti$\mathrm{S}$ protein antibody titers were observed (Ni et al., 2020; Prevost et al., 2020; Salazar et al., 2020; Wu et al., 2020a). Neutralizing antibody titers were also strongly correlated with the numbers of virus-specific T cells (Ni et al., 2020), suggesting coordinated humoral and cellular immune responses. The anti-SARS-CoV-2 antibodies in COVID-19 patients exhibit cross-reactivity and cross-neutralizing capability to SARS-CoV. Antibodies to $\mathrm{S}$ and $\mathrm{N}$ proteins of SARS-CoV-2 react to $\mathrm{S}$ and $\mathrm{N}$ antigens from SARS-CoV (Guo et al., 2020; Long et al., 2020a; Prevost et al., 2020). Anti-SARS-CoV-2 $\mathrm{S}$ protein antibodies neutralize SARSCoV S protein pseudotyped viral particles (Prevost et al., 2020). Importantly, convalescent serum samples collected from the 2003 SARS outbreak cross-reacted with the S protein of SARS-CoV-2 and neutralized SARS-CoV-2 infection (Zhu et al., 2020c). Thus, neutralizing antibodies to SARS-CoV-2 were readily produced in COVID-19 patients. The anti-SARS-CoV-2 antibodies were cross-reactive and 
cross-neutralizing to SARS-CoV and vice versa.

Do anti-SARS-CoV-2 antibodies pre-exist? Studies by Diez et al. characterized antibody reactivities and neutralizing capabilities to SARS-CoV-2, SARS-CoV, and MERS in commercial IVIG products (Diez et al., 2020a; Diez et al., $2020 \mathrm{~b}$ ). The IVIG products were generated with plasma collected in the US and European countries from March 2018 to October 2019. The IVIG products exhibited cross-reactivities to components of SARS-CoV-2, SARS-CoV, and MERS-CoV (Diez et al., 2020a). Interestingly, the IVIG preparations had neutralizing activities to SARS-CoV-2 and SARS-CoV but not MERS-CoV (Diez et al., 2020b). These studies indicate pre-existing cross-reactive antibodies in the general population and provide a potential source of treatment for COVID-19 patients. Furthermore, anti-SARS-CoV $-2 \mathrm{~S}$ protein antibodies were detectable in uninfected populations with high prevalence in children and adolescents $(\mathrm{Ng}$ et al., 2020). The antigen-specific antibodies were predominantly anti-S2 subunit IgG class. This antibody feature is in contrast to SARS-CoV-2 infection induced anti-S1 and -S2 subunit IgM, IgA and IgG class antibodies ( $\mathrm{Ng}$ et al., 2020). Thus, anti-SARS-CoV-2 preexisting and infectioninduced humoral immunities have distinct features.

\section{Are recovered COVID-19 patients protected from reinfection?}

As discussed above, although a majority of COVID-19 patients developed one or more antigen-specific antibodies to SARS-CoV-2, the rapid decline of antibodies in most of the convalescent COVID-19 patients and the weak antibody responses in asymptomatic and mild cases as well as immunosuppressed patients suggest that SARS-CoV-2 reinfection may be more common than currently appreciated. Numerous case reports have been published on COVID-19 reinfection (An et al., 2020; Lee et al., 2020a; Li et al., 2020a; McGrath et al., 2020; Prado-Vivar et al., 2020; Sanyaolu et al., 2020; Selvaraj et al., 2020; Tillett et al., 2020; To et al., 2020a; Torres et al., 2020). One report showed that three patients free of viral load but having low levels of anti$\mathrm{S}$ and $\mathrm{N}$-specific antibodies were re-infected ( $\mathrm{Li}$ et al., 2020a). In another report, three healthcare workers exhibited distinct episodes of recurrent symptoms after initial resolution and re-detection of SARS-CoV-2 RNA up to 60 days after disease onset (McGrath et al., 2020). Furthermore, 262 recovered and discharged COVID-19 patients were followed for re-occurrence (reinfection) for at least two weeks in Shenzhen, China and 38 of the patients became re-detectably positive for SARS-CoV-2 RNA (An et al., 2020). The authors attributed the re-detection of SARS-CoV-2 RNA to long-term carriers of the virus, as shown by others (Avanzato et al., 2020; Fu et al., 2020; Lan et al., 2020). The COVID-19 caused by SARS-CoV-2 reinfections may be more severe than the primary infection (Lee et al., 2020a; Selvaraj et al., 2020; Torres et al., 2020). The diagnosis of SARS-CoV-2 reinfection requires a high technical hurdle (different sequences of the viral strains involved). Thus, reinfection cases are likely underdiagnosed. As the antibodies begin to wane off in recovered COVID-19 patients infected months ago, many more reinfections will likely occur.

\section{Convalescent plasma and IVIG treatment of COVID-19 patients}

Antibody-based therapy is an important strategy for infectious disease prevention and treatment. Given the lack of effective and specific SARS-CoV-2 inhibitors, neutralizing antibodies in convalescent plasma (CP) from recovered COVID-19 patients represent a potential treatment to reduce viremia and improve patients' conditions. This therapy has been approved by regulatory agencies in several countries. Limited previous clinical experiences with $\mathrm{CP}$ treatment in SARS-CoV, MERS, influenza, and Ebola suggest that CP may provide benefits to COVID-19 patients (Bloch et al., 2020; Devasenapathy et al., 2020). Many recent reports have documented clinical outcomes of CP treatment in severe and critically ill COVID-19 patients (Ahn et al., 2020; Duan et al., 2020; Ibrahim et al., 2020; Jin et al., 2020; Keith et al., 2020; Li et al., 2020a; Li et al., 2020b; Liu et al., 2020a; Madariaga et al., 2020; Maor et al., 2020; Pei et al., 2020; Perotti et al., 2020; Dwi Putera and Suci Hardianti, 2020; Shen et al., 2020a; Wang et al., 2020c; Ye et al., 2020a; Zhang et al., 2020a). Two categories of results are presented. First, CP treatment demonstrated clinical efficacy in severe and critically ill COVID-19 patients in most of these reports, including rapid conversion to negative viral tests, improved clinical symptoms such as fever and oxygen requirement, increased lymphocyte counts, decreased inflammation, and better survival for non-intubated patients. A second category of results show patients did not clinically benefit from CP treatment. Intubated and moribund critically ill COVID-19 patients did not have improved survival upon CP treatment (Li et al., 2020b; Liu et al., 2020a; Wang et al., 2020c).

Several caveats need to be considered in interpretation of these clinical efficacy reports. First, the strength of the data is limited by the sample size. Among the above studies, 11 reported CP treatment in 10 or less COVID-19 patients (Ahn et al., 2020; Duan et al., 2020; Jin et al., 2020; Keith et al., 2020; Li et al., 2020a; Madariaga et al., 2020; Pei et al., 2020; Shen et al., 2020a; Wang et al., 2020c; Ye et al., 2020a; Zhang et al., 2020a). Five studies treated 37-49 patients (Ibrahim et al., 2020; Liu et al., 2020a; Maor et al., 2020; Perotti et al., 2020; Dwi Putera and Suci Hardianti, 2020). Only one randomized trial wherein 52 patients received CP 
treatment was reported and the results demonstrated that $\mathrm{CP}$ therapy plus standard treatment in severe or life-threatening COVID-19 patients did not result in significant clinical improvement (Li et al., 2020b). Thus, randomized controlled studies with sufficient power are needed to establish the clinical efficacy of CP treatment in COVID-19 patients. Second, the treatment procedures varied in different studies. These include variables such as times to collect plasma, definition of recovered patients, methods to process $\mathrm{CP}$ products, antibody titers and amounts of the re-infused $\mathrm{CP}$, and patient selection criteria. The wide variations in these studies prevent comparison and solid conclusions on the efficacy of CP treatment in COVID-19 patients. Third, the timing to achieve clinical efficacy is critical. Administration of CP into severe and critically ill COVID-19 patients may be too late to stop an already over-activated immune system (Lu et al., 2020b).

IVIG products represent another potential antibody treatment as these products exhibit cross-reactivities and neutralizing capabilities to SARS-CoV-2 (Diez et al., 2020a; Diez et al., 2020b). Several studies reported clinical efficacies of IVIG infusion to treat severe and critically ill COVID-19 patients (Cao et al., 2020; Gharebaghi et al., 2020; Shao et al., 2020). In one study, three severe COVID19 patients receiving high-dose IVIG daily for 5 days had clinical improvement (Cao et al., 2020). In the second multicenter retrospective cohort study, 174 COVID-19 patients were treated with high-dose IVIG in comparison to 152 patients in the control group (Shao et al., 2020). Subgroup analysis demonstrated that critically ill patients had reduced mortality at 28 days, decreased inflammation, and improved organ functions. This study suggests that early treatment of COVID-19 patients within 7 days after admission with a high dose $\left(>15 \mathrm{~g} \mathrm{~d}^{-1}\right)$ is beneficial and may be an effective treatment strategy. Furthermore, in a randomized placebo-controlled double-blind clinical trial, 59 patients with severe COVID-19 who did not respond to initial treatment were treated with IVIG or placebo (Gharebaghi et al., 2020). The IVIG-treated patients had a significantly lower mortality rate $(20.0 \%$ vs. $48.3 \%)$, indicating that IVIG administration in this group of patients improves clinical outcome. Further larger scale clinical trials are needed to verify the clinical efficacy. The advantage of using IVIG products to treat COVID-19 patients is the relatively large supply of commercial products with uniform quality.

\section{Antibody-mediated pathogenesis in COVID-19 patients}

On one hand, antigen-specific antibodies protect hosts from infection and enhance pathogen clearance. On the other hand, antibodies may contribute to disease progression
(Figure 1B). A potential mechanism of antibody-mediated pathogenesis in COVID-19 patients is ADE (Arvin et al., 2020; Eroshenko et al., 2020; Fierz and Walz, 2020; Lee et al., 2020b). ADE refers to a process by which antigen-specific antibodies enhance viral entry and replication in host cells and increase infectivity and virulence. ADE has been observed in several types of viral infections including dengue virus, Zika virus, Ebola virus, and coronaviruses SARSCoV and MERS-CoV (Peiris et al., 2003; Wang et al., 2014; Bardina et al., 2017; Katzelnick et al., 2017; Kuzmina et al., 2018; Liu et al., 2019; Wan et al., 2020b). To date, there is no report demonstrating a role for ADE in COVID-19 pathogenesis. However, several features of antibody responses in COVID-19 patients suggest that ADE may contribute to disease severity. First, as discussed above, the levels of antiSARS-CoV-2 antibodies are correlated with COVID-19 disease severity (Kutsuna et al., 2020; Li et al., 2020a; Liu et al., 2020c; Lynch et al., 2020; Wang et al., 2020e; Zhang et al., 2020b; Zhao et al., 2020). Severe and critically ill COVID-19 patients had significantly higher anti-SARSCoV-2 antibody titers than mild and asymptomatic cases. Although it was thought that ADE is primarily mediated through weak neutralizing or non-neutralizing antibodies (Arvin et al., 2020), a study showed that patients with worse clinical classification had higher neutralizing antibody titers (Wang et al., 2020e). The different classes of anti-SARSCoV-2 antibodies likely play distinct roles in COVID-19 pathogenesis. Second, it was observed that a significant number of COVID-19 patients had IgG seroconversion earlier than IgM (Long et al., 2020a). This phenomenon may be caused by cross-reactive $\mathrm{B}$ cell responses to other coronavirus family members previously infecting the hosts (Tetro, 2020). Consistent with this notion, IVIG products contain cross-reactive antibodies to SARS-CoV, MERSCoV, and SARS-CoV-2 (Diez et al., 2020a). The early production of anti-SARS-CoV-2 IgG may facilitate ADE. Third, it was observed that children with COVID-19 have milder symptoms and better prognoses than adults (Ludvigsson, 2020), and age is a significant determinant in COVID-19 severity (Cummings et al., 2020; Yang et al., 2020; Zhou et al., 2020a). Consistent with the above clinical manifestation, adult COVID-19 patients have higher titers of anti-SARSCoV-2 antibodies than children (Pierce et al., 2020; Weisberg et al., 2020). Together, these features of antibody responses support the hypothesis that rapid and increased induction of antigen-specific IgG upon SARS-CoV-2 infection in adults may result in ADE and contribute to COVID-19 pathogenesis (Fierz and Walz, 2020) (Figure 1B).

Another potential mechanism of antibody-mediated pathogenesis in COVID-19 patients may be the production of autoantibodies in severe and critically ill patients (Figure 1B). Severe/critically ill patients with clinically significant coagulopathy were reported to have antiphospholipid (anti- 
cardiolipin (CL) and anti- $\beta 2$-glycoprotein I ( $\beta 2 \mathrm{GPI})$ ) IgA, IgM, and IgG antibodies (Sung and Anjum, 2020; Vlachoyiannopoulos et al., 2020; Zhang et al., 2020f; Zuo et al., 2020). Higher titers of antiphospholipid antibodies were associated with increased release of neutrophil extracellular traps (NETs) (Zuo et al., 2020). NETs infiltrate the lung airway, interstitial, and vascular compartments in severe COVID-19 patients and contribute to pathogenesis (Radermecker et al., 2020). Furthermore, autoantibodies related to systemic autoimmune rheumatic diseases including antinuclear antibodies (ANA), anti-neutrophil cytoplasmic antibodies (ANCA), anti-extractable nuclear antigens (ENA), anti-dsDNAs, and anti-cyclic citrullinated peptide (CCP), as well as anti-phospholipid antibodies, were detected in 20/29 (68.7\%) patients (Vlachoyiannopoulos et al., 2020). Importantly, none of these patients had a history of systemic autoimmune rheumatic disease. Similarly, rheumatoid factor, ANA, and ANCA were detected in another cohort of severe and critically ill COVID-19 patients (Mobini et al., 2020). A recent report showed that $10.2 \%$ (101/987) of patients with life-threatening COVID-19 pneumonia had neutralizing IgG autoantibodies against IFN- $\omega$ and IFN- $\alpha$ at the onset of the critical disease. These autoantibodies neutralize high concentrations of type I IFNs, providing another potential underlying mechanism for life-threatening COVID-19 infection (Bastard et al., 2020). These clinical findings suggest that SARS-CoV-2 infection may induce autoimmune activation. This is supported by a recent study showing that critically ill COVID-19 patients display lupus-like hallmarks of extrafollicular B cell activation (Woodruff et al., 2020). B cells from critically ill COVID-19 patients were enriched for extrafollicular responses and induced to generate large numbers of antibody secreting cells. These features of B cell responses were associated with high rates of mortality in COVID-19 patients (Woodruff et al., 2020). Thus, the above studies suggest that SARS-CoV-2 infection in some patients induces autoimmune activation and production/amplification of autoantibodies. The autoantibodies contribute to COVID19 pathogenesis through antibody-mediated organ damage.

\section{Neutralizing monoclonal antibodies to SARS-CoV-2}

Neutralizing monoclonal antibodies (mAbs) offer great potential for developing biological drugs for the prevention and treatment of SARS-CoV-2 infection (Jiang et al., 2020). In the past 9 months, a large panel of neutralizing mAbs to SARS-CoV-2 antigens have been isolated. These neutralizing $\mathrm{mAbs}$ were derived from four different sources. The largest panel of neutralizing antibodies is from the peripheral blood of COVID-19 patients via sorting antigen-specific B lymphocytes and cloning paired heavy and light chains of anti-SARS-CoV-2-specific immunoglobulin (Brouwer et al.,
2020; Chi et al., 2020; Hansen et al., 2020; Ju et al., 2020; Robbiani et al., 2020; Rogers et al., 2020; Seydoux et al., 2020; Shi et al., 2020; Tortorici et al., 2020; Wan et al., 2020a; Wu et al., 2020c; Zost et al., 2020) (Table 2). The second category of neutralizing mAbs were identified from previously isolated anti-SARS-CoV mAbs by testing their cross-reactivities to SARS-CoV-2 antigens (Ejemel et al., 2020; Huo et al., 2020; Pinto et al., 2020; Tai et al., 2020; Tian et al., 2020; Wec et al., 2020; Yuan et al., 2020b). The third category of neutralizing mAbs were developed in humanized mice by immunizing with $\mathrm{S}$ protein (Ejemel et al., 2020; Hansen et al., 2020; Wang et al., 2020a), and the fourth category of mAbs were identified by panning of phage or yeast-displayed libraries (Liu et al., 2020b; Lv et al., 2020; Noy-Porat et al., 2020; Schoof et al., 2020; Sun et al., 2020; Wu et al., 2020b; Yuan et al., 2020a; Zeng et al., 2020).

This rapid isolation of many neutralizing antibodies is a testament to the impressive worldwide effort in the search for means to treat and prevent COVID-19. Several important characteristics are reported about these neutralizing antibodies. The antibodies are selected from large pools of binding antibodies and have high affinity and potent neutralizing efficacy in blocking infections by pseudotyped virus and/or authentic SARS-CoV-2. Surprisingly, few antibodies isolated from COVID-19 patients cross-react to SARS-CoV antigens despite high homology between these two viruses. In contrast, efforts to screen cross-reactivities to SARS-CoV-2 in previously isolated neutralizing antibodies to SARS-CoV was fruitful (Ejemel et al., 2020; Huo et al., 2020; Pinto et al., 2020; Tai et al., 2020; Tian et al., 2020; Wec et al., 2020; Yuan et al., 2020b). Furthermore, most of these neutralizing antibodies bind to epitopes in the RBD; several also bind to the NTD (Table 2). Epitope mapping and crystal structure studies of the antibodies revealed various binding sites in the RBD (Brouwer et al., 2020; Hansen et al., 2020; Huo et al., 2020; Ju et al., 2020; Pinto et al., 2020; Robbiani et al., 2020; Rogers et al., 2020; Seydoux et al., 2020; Shi et al., 2020; Wan et al., 2020a; Wu et al., 2020c; Xiang et al., 2020; Zost et al., 2020). Some neutralizing antibodies bind to the ACE2 interaction sites on RBD, therefore sterically hindering viral engagement, while others bind to non-ACE2 interacting areas on RBD. The antibodies' differential recognition of epitopes on RBD and NTD provides candidates for developing therapeutic antibody cocktails to prevent virus escape mutants. Indeed, a potent neutralizing antibody $\mathrm{CC} 6.33$ needed a 10 -fold higher $\mathrm{IC}_{50}$ to neutralize a mutant (V367F) strain while another antibody CC6.29 completely lost its neutralizing capability to another mutant strain (G476S) compared to their neutralizing capability to the wildtype WA-1 strain (Rogers et al., 2020). Escape mutants rapidly arise in the presence of individual neutralizing antibodies but fail to generate after treatment with a noncompeting antibody cocktail (Baum et al., 2020b). 
Table 2 A partial list of isolated neutralizing antibodies to SARS-CoV-2 ${ }^{\text {a) }}$

\begin{tabular}{|c|c|c|c|c|c|c|c|c|}
\hline Antibody & Name & Source & $\begin{array}{l}\text { Neutralizing efficacy } \\
\left(\mu \mathrm{g} \mathrm{mL}{ }^{-1}\right)\end{array}$ & $\begin{array}{c}\text { Binding } \\
\left(\mathrm{kd}, \mathrm{nmol} \mathrm{L}^{-1}\right)\end{array}$ & $\begin{array}{l}\text { In vivo } \\
\text { activity }\end{array}$ & Domain & $\begin{array}{l}\text { Cross-reactivity } \\
\text { to SARS-CoV }\end{array}$ & Reference \\
\hline 1 & 47D11 & hu-Mice & 0.57 & 10.8 & N/A & RBD & Yes & (Wang et al., 2020a) \\
\hline 2 & CA1 & Human & 0.38 & 4.68 & N/A & RBD & No & (Shi et al., 2020) \\
\hline 3 & CB6 & Human & 0.036 & 2.49 & Yes & RBD & No & (Shi et al., 2020) \\
\hline 4 & $4 \mathrm{~A} 8$ & Human & 0.61 & 92.7 & $\mathrm{~N} / \mathrm{A}$ & NTD & No & (Chi et al., 2020) \\
\hline 5 & B38 & Human & 0.177 & 70.1 & Yes & RBD & No & (Wu et al., 2020c) \\
\hline 6 & $\mathrm{H} 4$ & Human & 0.896 & 4.48 & Yes & RBD & No & (Wu et al., 2020c) \\
\hline 7 & CV30 & Human & 0.03 & 3.6 & N/A & RBD & No & (Seydoux et al., 2020) \\
\hline 8 & 7 clones & Human & $0.03-35.87$ & $2.12-21.29$ & N/A & RBD & No & (Ju et al., 2020) \\
\hline 9 & 11 clones & Human & $1.75-50$ & $1.84-54.65$ & N/A & $\mathrm{RBD} / \mathrm{NTD}$ & Yes for 3 & (Wan et al., 2020a) \\
\hline 10 & CCL12.1 ${ }^{* *}$ & Human & 0.022 & 5.92 & Yes & RBD & No & (Rogers et al., 2020) \\
\hline 11 & COVA1-12 $2^{* * *}$ & Human & 1.4 & 2.7 & N/A & RBD & No & (Brouwer et al., 2020) \\
\hline 12 & 9 clones & hu-Mice/Hu & $7.23-99.1 \mathrm{pmol} \mathrm{L}^{-1}$ & $0.56-45.2$ & $\mathrm{~N} / \mathrm{A}$ & RBD & Yes & (Hansen et al., 2020) \\
\hline 13 & CR3022 & Human $^{*}$ & 0.114 & $6.3-115$ & N/A & RBD & Yes & $\begin{array}{l}\text { (Huo et al., 2020; Tian et al., } \\
\text { 2020; Yuan et al., 2020b) }\end{array}$ \\
\hline 14 & S309 & Human ${ }^{*}$ & 0.079 & $<0.001$ & N/A & RBD & Yes & (Pinto et al., 2020) \\
\hline
\end{tabular}

a) hu-Mice: humanized mice. Neutralizing efficacy was reported as $\mathrm{IC}_{50}, \mathrm{ND}_{50}$, or $\mathrm{ID}_{50}$. N/A: not available. *: from SARS-CoV patient. **: representative of 33 clones. ***: representative of 19 clones.

Thus, combined use of various neutralizing mAbs recognizing distinct epitopes is needed in future prevention and treatment.

Several neutralizing antibodies have been tested for their in vivo preventive and therapeutic efficacies in different SARS-CoV-2 infection animal models (Rogers et al., 2020; Shi et al., 2020; Wu et al., 2020c). The CB6 mAb was tested in rhesus macaques in both prophylactic and treatment settings (Shi et al., 2020). Administration of the mAb at $50 \mathrm{mg} \mathrm{kg}^{-1}$ reduced virus titers by $\sim 3 \log _{10}$ compared to PBS treated groups. Prophylactic injection of the $\mathrm{mAb}$ at $50 \mathrm{mg} \mathrm{kg}^{-1}$ significantly reduced viral infection (Shi et al., 2020). In the hACE2 transgenic mouse model, a single $25 \mathrm{mg} \mathrm{kg}^{-1}$ dose of neutralizing antibodies administered separately after virus challenge reduced the viral RNA copies in the lung of the infected mice by $2-3 \log _{10}$ (Wu et al., 2020c). In a Syrian hamster model, administration of neutralizing mAbs at $4.2-16.5 \mathrm{~kg} \mathrm{mg}^{-1}$ completely prevented SARS-CoV-2-induced bodyweight loss in the infected animals (Rogers et al., 2020). Furthermore, REGN-COV2, a combination of two mAbs (REGN10987+REGN10933) targeting non-overlapping epitopes on the $\mathrm{S}$ protein of SARS-CoV-2, displayed potent in vivo virus neutralization prophylactically and therapeutically in rhesus macaques and hamsters (Baum et al., 2020a). Importantly, neutralizing mAbs to SARS-CoV-2 have been clinically tested in COVID-19 patients. Administration of REGN-COV2 reduced COVID-19-related hospitalization or emergency room visits and was thus granted Emergency Use Authorization by the US Food and Drug Administration on November 21, 2020. In an ongoing phase II clinical trial, mild and moderate
COVID-19 patients treated with a single intravenous infusion of the neutralizing antibody LY-CoV555 demonstrated efficacy in reducing viral load in the patients (Chen et al., 2020a). Together, these preclinical and clinical studies provide very promising results for clinical use of neutralizing mAbs to treat COVID-19 patients.

\section{Progress of COVID-19 vaccine development}

The S protein of SARS-CoV-2 is the primary target for COVID-19 vaccines due to its critical role in host infectivity. Many different forms of vaccines are under intensive development (Tse et al., 2020; Zhang et al., 2020d). The COVID-19 vaccine candidates were tested in in vivo infected animal models. A series of DNA vaccine candidates expressing different forms of the $\mathrm{S}$ protein showed protective effects by reducing SARS-CoV-2 by $3-4 \log _{10}$ in nonhuman primates (Yu et al., 2020b). A purified inactivated SARS$\mathrm{CoV}-2$ virus vaccine induced neutralizing antibodies in mice, rats, and nonhuman primates and provided partial or complete protection in macaques against virus challenge (Gao et al., 2020). Results from measles virus and vesicular stomatitis virus (VSV) based vaccine candidates in animal models were also reported (Horner et al., 2020; Yahalom-Ronen et al., 2020). Three studies reported preliminary results on the safety and immunogenicity of inactivated COVID-19 vaccines from phase I/II clinical trials (Che et al., 2020; Xia et al., 2020a; Zhang et al., 2020g). The inactivated vaccines demonstrated acceptable safety profiles and were effective in inducing neutralizing antibodies. The clinical trial results 
support further development of the inactivated COVID-19 vaccines.

Development of two major forms of COVID-19 vaccines, mRNA-nanoparticle-based and adenovirus-vectored, has made rapid progress, with both reporting results from phase III clinical trials recently. In a phase I study, administration of mRNA-1273 vaccine encoding a stabilized prefusion S protein trimer to 45 healthy adults (18-55 years old) resulted in production of neutralizing antibodies in all participants at levels similar to or higher than those in convalescent sera (Jackson et al., 2020). The vaccine injected once or twice at three doses $(25,100$, and $250 \mu \mathrm{g})$ was safe with no serious adverse events. Furthermore, a Th-1-biased $\mathrm{CD} 4{ }^{+} \mathrm{T}$ cell response was induced by mRNA-1273 vaccination. In another small study involving old adults ( $>56$ years old), mRNA-1273 at 25 and $100 \mu \mathrm{g}$ also demonstrated good safety and efficacy profiles (Anderson et al., 2020). Importantly, mRNA-1273 was recently tested in a large phase III COVE trial with $>30,000$ participants (NCT04470427) and demonstrated a 94.5\% rate of protection against COVID-19 (https://investors. modernatx.com/node/10316/pdf ). On November 25, 2020, the European Commission approved an initial purchase of 80 million doses of mRNA-1273 from its manufacturer Moderna Inc. for immunization of the general population (https:// investors.modernatx.com/node/10366/pdf).

Another mRNA-nanoparticle-based COVID-19 vaccine, BNT162b1/b2, has also made rapid clinical progress. In a phase I study, BNT162b1, a lipid nanoparticle-formulated, nucleoside-modified mRNA vaccine was immunized twice in 45 18-55-year-old healthy adults at 3 different doses (10, 30, and $100 \mu \mathrm{g}$ ) (Mulligan et al., 2020). Neutralizing antibodies were induced to titers higher than those in convalescent plasma, while the vaccine was well tolerated with generally mild to moderate local reactions and systemic events. T cell responses were not reported in this study (Mulligan et al., 2020). BNT162b1 vaccination not only induced high titers of neutralizing antibodies but also elicited robust antigen specific $\mathrm{CD}^{+}$and $\mathrm{CD} 8^{+} \mathrm{T}$ cell responses (Sahin et al., 2020). A second form of the BNT162 COVID19 vaccine, b2, has been tested clinically in comparison to BNT162b1 (Walsh et al., 2020). In contrast to BNT162b1 which encodes a secreted trimerized SARS-CoV-2 RBD, BNT162b2 encodes a membrane-anchored SARS-CoV-2 full-length $\mathrm{S}$ that is stabilized in the prefusion conformation. Both forms of BNT162 vaccine induced similar dose-dependent neutralizing antibodies but the BNT162b2 form was associated with a lower incidence and severity of systemic reactions than BNT162b1, particularly in older adults (Walsh et al., 2020). Importantly, in a large phase III trial with 43,538 participants (NCT04368728), BNT162b2 showed a 95\% efficacy rate against SARS-CoV-2 infection (https:// www.pfizer.com/news/press-release/press-release-detail/pfizer-and-biontech-conclude-phase-3-study-covid-19-vac- cine). The BNT162b2 vaccine received regulatory approval in UK on December 2, 2020.

Two independent adenovirus-vectored SARS-CoV-2 vaccines have been tested in human trials. A human adenovirus type-5 (Ad5) vectored COVID-19 vaccine was administered to a total of 490 adults 18 years and older in phase I and II trials (Zhu et al., 2020a; Zhu et al., 2020b). Ad5-vectored COVID-19 expressing a full-length $\mathrm{S}$ protein was injected intramuscularly once or twice at three doses of $5 \times 10^{10}$, $1 \times 10^{11}$, and $1.5 \times 10^{11}$ viral particles per mL. Most of the participants (96\%-97\%) were seropositive at day 28 with significantly elevated neutralizing antibodies (Zhu et al., 2020a). Furthermore, antigen-specific T cell responses were observed in $\sim 90 \%$ of the subjects. Although adverse events were reported in $77 \%$ of participants, no serious events were documented. However, some weaknesses for this vaccine candidate were noted. Humoral responses were lower in people over 55 years of age and $52 \%$ of participants with high pre-existing anti-Ad5 vector neutralizing antibody titers (Zhu et al., 2020a).

A chimpanzee adenovirus-vectored vaccine termed ChAdOx1 nCOVID-19 was tested in a randomized controlled phase I/II trial in 543 participants aged $18-55$ years with the same number of participants receiving meningococcal conjugate vaccine as controls (Folegatti et al., 2020). Seroconversion was observed in all participants. Neutralizing antibodies were positive in all 35 tested participants, and antigen-specific $\mathrm{T}$ cell responses were induced in all 43 tested participants, suggesting strong immunogenicity. Furthermore, ChAdOx1 nCOVID-19 vaccine was safe with no serious adverse events. The ChAdOx1 was further investigated in a phase II/III trial (COV002) with adults at different ages including seniors $>70$ years old (Ramasamy et al., 2020). The participants received primer-boost immunization of low- and standard-dose ChAdOx1 nCOVID19 vaccine. The vaccine showed similar immunogenicity in all age groups after a boost dose but appeared to be better tolerated in older adults than in younger adults (Ramasamy et al., 2020). On November 23, 2020, a preliminary analysis of phase III trial of ChAdOx1 nCOVID-19 vaccine revealed an average $70 \%$ effective rate (Callaway, 2020). Participants receiving two full doses of prime-boost immunization had a $62 \%$ effective rate while those receiving a lower dose of prime and a full dose of boost immunization had a $90 \%$ effective rate (Callaway, 2020). These data suggest that adenovirus-vectored SARS-CoV-2 vaccines are good candidates for COVID-19 vaccine.

\section{Significance of antibody responses in vaccine development}

The above discussed antibody responses from recent clinical 
studies on COVID-19 patients have important implications in vaccine development (Figure 1C). The first implication is in the safety of the vaccines. Both mRNA-nanoparticle and adenovirus-vectored vaccines have demonstrated overall acceptable safety profiles in phase I/II/III trials. The local and systemic events such as pain, fever, fatigue, chills, muscle ache, headache, and other symptoms were generally mild/modest and can be further alleviated with prophylactic paracetamol administration (Folegatti et al., 2020; Jackson et al., 2020; Mulligan et al., 2020; Ramasamy et al., 2020; Walsh et al., 2020; Zhu et al., 2020a; Zhu et al., 2020b). However, ADE of disease severity, the critical adverse event that may be induced after vaccination, has yet to be determined in the human population upon SARS-CoV-2 infection (Arvin et al., 2020). Several studies have demonstrated ADE of disease severity upon immunization with different forms of SARS-CoV vaccines and re-challenge of SARS-CoV live virus in mice, ferrets, and nonhuman primates (Weingartl et al., 2004; Bolles et al., 2011; Tseng et al., 2012; Wang et al., 2016). The vaccine-induced immunopathology includes increased lung infiltration of eosinophils, neutrophils, and monocytes and enhanced hepatitis. Aged animals displayed severe immune pathology and were not effectively protected against virus replication, possibly caused by development of autoantibodies (Bolles et al., 2011). Importantly, severe and critically ill COVID-19 patients had significantly higher anti-SARS-CoV-2 antibody titers than mild and asymptomatic cases. Thus, these observations raise important questions on the safety of COVID19 vaccines: whether the immunized people develop ADE of disease severity and whether they have full protection against SARS-CoV-2 infection, especially in aged human populations. These critical questions will hopefully be adequately addressed in large trials carried out in COVID-19 pandemic areas.

The second implication of the antibody responses in SARS-CoV-2-infected populations is related to the efficacy of COVID-19 vaccines. As discussed, although most COVID-19 patients developed antigen-specific antibodies to SARS-CoV-2, the antibodies decline rapidly in convalescent COVID-19 patients. Furthermore, asymptomatic/mild cases and immunosuppressed patients develop weak antibody responses. In light of these findings, the idea to develop herd immunity by wide-spread natural infection may not be feasible given that most infected persons are mild or asymptomatic. The clinical trial results showing that mRNA- and adenovirus-based COVID-19 vaccines induce antibody titers similar to or higher than those in CP of COVID-19 patients are encouraging (Folegatti et al., 2020; Jackson et al., 2020; Mulligan et al., 2020; Zhu et al., 2020a; Zhu et al., 2020b). However, it remains unknown whether these vaccines can induce long-lasting protective neutralizing antibodies and antigen-specific cellular immunity.
The third implication of the antibody responses in COVID19 patients relates to the efficacy of vaccines in neutralizing SARS-CoV-2 mutants. One of the major mutations in the SARS-CoV-2 genome with biological significance is a point $\mathrm{D}$ to $\mathrm{G}$ change at position 614 in the S protein, now accounting for $97 \%$ of isolates worldwide (Korber et al., 2020). The D614G SARS-CoV-2 variant has several advantages over the wildtype virus including 3-10-fold more infectivity, growing to higher titers in vitro, and being more abundant in the respiratory tract ( $\mathrm{Hu}$ et al., 2020; Korber et al., 2020; Yurkovetskiy et al., 2020; Zhang et al., 2020e). Although some neutralizing mAbs retained reactivity to the D614G variant (Rogers et al., 2020; Yurkovetskiy et al., 2020), it was reported that $7 \%(3 / 41)$ of convalescent sera had decreased neutralizing activity against the G614 mutation ( $\mathrm{Hu}$ et al., 2020). Furthermore, some of the neutralizing mAbs lost their capacity to inhibit viral replication of other point mutation variants (G476S, V367F) (Rogers et al., 2020). Thus, a critical issue in COVID-19 vaccine development is to maintain protective immunity against SARS-CoV-2 escape mutants.

In summary, the recent progress in characterization of antibody response and experimental treatment in COVID-19 patients as well as the isolation of a large panel of mAbs has shed light on the pathophysiology and immunobiology of SARS-CoV-2 infection. The results from clinical trials of several COVID-19 vaccine candidates have provided great hope, but major issues need to be addressed for eventual control of the COVID-19 pandemic.

Compliance and ethics You-Wen He and Shi-You Li are shareholders of tricision Biotherapeutic Inc.

Acknowledgements This work is supported by the National Key Research and Development Program of China (2017YFA0205200), the National Natural Science Foundation of China (81571785, 81771957, 81901857, 81801811), Natural Science Foundation of Guangdong Province, China (2018A030313074) to Dr. Ligong Lu, the Zhuhai Municipal Science and Technology Foundation (ZH22046301200004PWC) to Dr. Shi-You Li, and the Sunny Li Family fund to You-Wen He.

\section{References}

Ahn, J.Y., Sohn, Y., Lee, S.H., Cho, Y., Hyun, J.H., Baek, Y.J., Jeong, S.J., Kim, J.H., Ku, N.S., Yeom, J.S., et al. (2020). Use of convalescent plasma therapy in two COVID-19 patients with acute respiratory distress syndrome in Korea. J Korean Med Sci 35, e149.

An, J., Liao, X., Xiao, T., Qian, S., Yuan, J., Ye, H., Qi, F., Shen, C., Wang, L., Liu, Y., et al. (2020). Clinical characteristics of recovered COVID19 patients with re-detectable positive RNA test. Ann Transl Med 8, 1084.

Anderson, E.J., Rouphael, N.G., Widge, A.T., Jackson, L.A., Roberts, P.C., Makhene, M., Chappell, J.D., Denison, M.R., Stevens, L.J., Pruijssers, A.J., et al. (2020). Safety and Immunogenicity of SARS-CoV-2 mRNA1273 Vaccine in Older Adults. N Engl J Med NEJMoa2028436.

Arvin, A.M., Fink, K., Schmid, M.A., Cathcart, A., Spreafico, R., HavenarDaughton, C., Lanzavecchia, A., Corti, D., and Virgin, H.W. (2020). A perspective on potential antibody-dependent enhancement of SARS- 
CoV-2. Nature 584, 353-363.

Avanzato, V.A., Matson, M.J., Seifert, S.N., Pryce, R., Williamson, B.N., Anzick, S.L., Barbian, K., Judson, S.D., Fischer, E.R., Martens, C., et al. (2020). Case study: prolonged infectious SARS-CoV-2 shedding from an asymptomatic immunocompromised individual with cancer. Cell, doi: 10.1016/j.cell.2020.10.049.

Bampoe, S., Lucas, D.N., Neall, G., Sceales, P., Aggarwal, R., Caulfield, K., Siassakos, D., and Odor, P.M. (2020). A cross-sectional study of immune seroconversion to SARS-CoV-2 in frontline maternity health professionals. Anaesthesia 75, 1614-1619.

Bardina, S.V., Bunduc, P., Tripathi, S., Duehr, J., Frere, J.J., Brown, J.A., Nachbagauer, R., Foster, G.A., Krysztof, D., Tortorella, D., et al. (2017). Enhancement of Zika virus pathogenesis by preexisting antiflavivirus immunity. Science 356, 175-180.

Bastard, P., Rosen, L.B., Zhang, Q., Michailidis, E., Hoffmann, H.H., Zhang, Y., Dorgham, K., Philippot, Q., Rosain, J., Béziat, V., et al. (2020). Autoantibodies against type I IFNs in patients with lifethreatening COVID-19. Science 370, eabd4585.

Baum, A., Ajithdoss, D., Copin, R., Zhou, A., Lanza, K., Negron, N., Ni, M., Wei, Y., Mohammadi, K., Musser, B., et al. (2020a). REGN-COV2 antibodies prevent and treat SARS-CoV-2 infection in rhesus macaques and hamsters. Science 370, 1110-1115.

Baum, A., Fulton, B.O., Wloga, E., Copin, R., Pascal, K.E., Russo, V., Giordano, S., Lanza, K., Negron, N., Ni, M., et al. (2020b). Antibody cocktail to SARS-CoV-2 spike protein prevents rapid mutational escape seen with individual antibodies. Science eabd0831.

Bloch, E.M., Shoham, S., Casadevall, A., Sachais, B.S., Shaz, B., Winters, J.L., van Buskirk, C., Grossman, B.J., Joyner, M., Henderson, J.P., et al. (2020). Deployment of convalescent plasma for the prevention and treatment of COVID-19. J Clin Invest 130, 2757-2765.

Bolles, M., Deming, D., Long, K., Agnihothram, S., Whitmore, A., Ferris, M., Funkhouser, W., Gralinski, L., Totura, A., Heise, M., et al. (2011). A double-inactivated severe acute respiratory syndrome coronavirus vaccine provides incomplete protection in mice and induces increased eosinophilic proinflammatory pulmonary response upon challenge. J Virol 85, 12201-12215.

Brouwer, P.J.M., Caniels, T.G., van der Straten, K., Snitselaar, J.L., Aldon, Y., Bangaru, S., Torres, J.L., Okba, N.M.A., Claireaux, M., Kerster, G., et al. (2020). Potent neutralizing antibodies from COVID-19 patients define multiple targets of vulnerability. Science 369, 643-650.

Callaway, E. (2020). Why Oxford's positive COVID vaccine results are puzzling scientists. Nature 588, 16-18.

Cao, W., Liu, X., Bai, T., Fan, H., Hong, K., Song, H., Han, Y., Lin, L., Ruan, L., and Li, T. (2020). High-dose intravenous immunoglobulin as a therapeutic option for deteriorating patients with coronavirus disease 2019. Open Forum Infect Dis 7, ofaa102.

Chakraborty, S., Gonzalez, J., Edwards, K., Mallajosyula, V., Buzzanco, A. S., Sherwood, R., Buffone, C., Kathale, N., Providenza, S., Xie, M.M., et al. (2020). Proinflammatory IgG Fc structures in patients with severe COVID-19. Nat Immunol, doi: 10.1038/s41590-020-00828-7.

Che, Y., Liu, X., Pu, Y., Zhou, M., Zhao, Z., Jiang, R., Yin, Z., Xu, M., Yin, Q., Wang, J., et al. (2020). Randomized, double-blinded and placebocontrolled phase II trial of an inactivated SARS-CoV-2 vaccine in healthy adults. Clin Infect Dis, doi: 10.1093/cid/ciaa1703.

Chen, P., Nirula, A., Heller, B., Gottlieb, R.L., Boscia, J., Morris, J., Huhn, G., Cardona, J., Mocherla, B., Stosor, V., et al. (2020a). SARS-CoV-2 Neutralizing Antibody LY-CoV555 in Outpatients with Covid-19. N Engl J Med NEJMoa2029849.

Chen, Y., Zuiani, A., Fischinger, S., Mullur, J., Atyeo, C., Travers, M., Lelis, F.J.N., Pullen, K.M., Martin, H., Tong, P., et al. (2020b). Quick COVID-19 Healers Sustain Anti-SARS-CoV-2 Antibody Production. Cell, doi: 10.1016/j.cell.2020.10.051.

Chi, X., Yan, R., Zhang, J., Zhang, G., Zhang, Y., Hao, M., Zhang, Z., Fan, P., Dong, Y., Yang, Y., et al. (2020). A neutralizing human antibody binds to the N-terminal domain of the Spike protein of SARS-CoV-2. Science 369, 650-655.

Cummings, M.J., Baldwin, M.R., Abrams, D., Jacobson, S.D., Meyer, B.J.,
Balough, E.M., Aaron, J.G., Claassen, J., Rabbani, L.R.E., Hastie, J., et al. (2020). Epidemiology, clinical course, and outcomes of critically ill adults with COVID-19 in New York City: a prospective cohort study. Lancet 395, 1763-1770.

de Haan, N., Reiding, K.R., Driessen, G., van der Burg, M., and Wuhrer, M. (2016). Changes in healthy human IgG Fc-glycosylation after birth and during early childhood. J Proteome Res $15,1853-1861$.

Deeks, J.J., Dinnes, J., Takwoingi, Y., Davenport, C., Spijker, R., TaylorPhillips, S., Adriano, A., Beese, S., Dretzke, J., Ferrante Di Ruffano, L., et al. (2020). Antibody tests for identification of current and past infection with SARS-CoV-2. Cochrane Datab Syst Rev, https://doi.org/ 10.1002/14651858.CD013652.

Devasenapathy, N., Ye, Z., Loeb, M., Fang, F., Najafabadi, B.T., Xiao, Y., Couban, R., Bégin, P., and Guyatt, G. (2020). Efficacy and safety of convalescent plasma for severe COVID-19 based on evidence in other severe respiratory viral infections: a systematic review and metaanalysis. CMAJ 192, E745-E755.

Diez, J.M., Romero, C., and Gajardo, R. (2020a). Currently available intravenous immunoglobulin contains antibodies reacting against severe acute respiratory syndrome coronavirus 2 antigens. Immunotherapy 12, 571-576.

Diez, J.M., Romero, C., Vergara-Alert, J., Belló-Perez, M., Rodon, J., Honrubia, J.M., Segalés, J., Sola, I., Enjuanes, L., and Gajardo, R. (2020b). Cross-neutralization activity against SARS-CoV-2 is present in currently available intravenous immunoglobulins. Immunotherapy 12 , $1247-1255$.

Duan, K., Liu, B., Li, C., Zhang, H., Yu, T., Qu, J., Zhou, M., Chen, L., Meng, S., Hu, Y., et al. (2020). Effectiveness of convalescent plasma therapy in severe COVID-19 patients. Proc Natl Acad Sci USA 117, 9490-9496.

Dwi Putera, D., and Suci Hardianti, M. (2020). Efficacy and safety of convalescent plasma therapy in patients with COVID-19: a rapid review of case series. JMedScie 52

Ejemel, M., Li, Q., Hou, S., Schiller, Z.A., Tree, J.A., Wallace, A., Amcheslavsky, A., Kurt Yilmaz, N., Buttigieg, K.R., Elmore, M.J., et al. (2020). A cross-reactive human IgA monoclonal antibody blocks SARS-CoV-2 spike-ACE2 interaction. Nat Commun 11, 4198.

Eroshenko, N., Gill, T., Keaveney, M.K., Church, G.M., Trevejo, J.M., and Rajaniemi, H. (2020). Implications of antibody-dependent enhancement of infection for SARS-CoV-2 countermeasures. Nat Biotechnol 38, 789-791.

Favresse, J., Eucher, C., Elsen, M., Graux, C., Goebels, P., Laffineur, K., Nicolas, J.B., Dogne, J.M., and Douxfils, J. (2020). Unexpected kinetics of anti-SARS-CoV-2 total antibodies in two patients with chronic lymphocytic leukemia. Br J Haematol 190.

Ferrara, C., Grau, S., Jäger, C., Sondermann, P., Brünker, P., Waldhauer, I., Hennig, M., Ruf, A., Rufer, A.C., Stihle, M., et al. (2011). Unique carbohydrate-carbohydrate interactions are required for high affinity binding between Fc $\gamma$ RIII and antibodies lacking core fucose. Proc Natl Acad Sci USA 108, 12669-12674.

Fierz, W., and Walz, B. (2020). Antibody dependent enhancement due to original antigenic sin and the development of SARS. Front Immunol 11, 1120.

Fiore, J.R., Centra, M., De Carlo, A., Granato, T., Rosa, A., Sarno, M., De Feo, L., Di Stefano, M., Errico, M.D., Caputo, S.L., et al. (2020). Results from a survey in healthy blood donors in South Eastern Italy indicate that we are far away from herd immunity to SARS-CoV-2. J Med Virol jmv.26425.

Flannery, D.D., Gouma, S., Dhudasia, M.B., Mukhopadhyay, S., Pfeifer, M. R., Woodford, E.C., Gerber, J.S., Arevalo, C.P., Bolton, M.J., Weirick, M.E., et al. (2020). SARS-CoV-2 seroprevalence among parturient women in Philadelphia. Sci Immunol 5, eabd5709.

Folegatti, P.M., Ewer, K.J., Aley, P.K., Angus, B., Becker, S., BelijRammerstorfer, S., Bellamy, D., Bibi, S., Bittaye, M., Clutterbuck, E.A., et al. (2020). Safety and immunogenicity of the ChAdOx1 nCoV-19 vaccine against SARS-CoV-2: a preliminary report of a phase $1 / 2$, single-blind, randomised controlled trial. Lancet 396, 467-478. 
Fontanet, A., and Cauchemez, S. (2020). COVID-19 herd immunity: where are we? Nat Rev Immunol 20, 583-584.

Fox, A., Marino, J., Amanat, F., Krammer, F., Hahn-Holbrook, J., ZollaPazner, S., and Powell, R.L. (2020). Robust and specific secretory IgA against SARS-CoV-2 detected in human milk. iScience 23, 101735.

Fu, W., Chen, Q., and Wang, T. (2020). Letter to the Editor: Three cases of redetectable positive SARS-CoV-2 RNA in recovered COVID-19 patients with antibodies. J Med Virol 92, 2298-2301.

Gao, Q., Bao, L., Mao, H., Wang, L., Xu, K., Yang, M., Li, Y., Zhu, L., Wang, N., Lv, Z., et al. (2020). Development of an inactivated vaccine candidate for SARS-CoV-2. Science 369, 77-81.

Gharebaghi, N., Nejadrahim, R., Mousavi, S.J., Sadat-Ebrahimi, S.R., and Hajizadeh, R. (2020). The use of intravenous immunoglobulin gamma for the treatment of severe coronavirus disease 2019: a randomized placebo-controlled double-blind clinical trial. BMC Infect Dis 20, 786.

Guo, L., Ren, L., Yang, S., Xiao, M., Chang, D., Yang, F., Dela Cruz, C.S., Wang, Y., Wu, C., Xiao, Y., et al. (2020). Profiling Early Humoral Response to Diagnose Novel Coronavirus Disease (COVID-19). Clin Infect Dis 71, 778-785.

Hansen, J., Baum, A., Pascal, K.E., Russo, V., Giordano, S., Wloga, E., Fulton, B.O., Yan, Y., Koon, K., Patel, K., et al. (2020). Studies in humanized mice and convalescent humans yield a SARS-CoV-2 antibody cocktail. Science eabd0827.

Hartenian, E., Nandakumar, D., Lari, A., Ly, M., Tucker, J.M., and Glaunsinger, B.A. (2020). The molecular virology of Coronaviruses. J Biol Chem 295, 12910-12934.

Harvala, H., Mehew, J., Robb, M.L., Ijaz, S., Dicks, S., Patel, M., Watkins, N., Simmonds, P., Brooks, T., Johnson, R., et al. (2020). Convalescent plasma treatment for SARS-CoV-2 infection: analysis of the first 436 donors in England, 22 April to 12 May 2020. Eurosurveillance 25.

Havers, F.P., Reed, C., Lim, T., Montgomery, J.M., Klena, J.D., Hall, A.J., Fry, A.M., Cannon, D.L., Chiang, C.F., Gibbons, A., et al. (2020). Seroprevalence of antibodies to SARS-CoV-2 in 10 sites in the United States, March 23-May 12, 2020. JAMA Intern Med, doi: 10.1001/ jamainternmed.2020.4130.

Hoffmann, M., Kleine-Weber, H., Schroeder, S., Krüger, N., Herrler, T., Erichsen, S., Schiergens, T.S., Herrler, G., Wu, N.H., Nitsche, A., et al. (2020). SARS-CoV-2 cell entry depends on ACE2 and TMPRSS2 and is blocked by a clinically proven protease inhibitor. Cell 181, 271-280. e8.

Horner, C., Schurmann, C., Auste, A., Ebenig, A., Muraleedharan, S., Herrmann, M., Schnierle, B., and Muhlebach, M.D. (2020). A highly immunogenic measles virus-based Th1-biased COVID-19 vaccine. bioRxiv, https://doi.org/10.1101/2020.07.11.198291.

Hu, J., He, C.L., Gao, Q.Z., Zhang, G.J., Cao, X.X., Long, Q.X., Deng, H. J., Huang, L.Y., Chen, J., Wang, K., et al. (2020). The D614G mutation of SARS-CoV-2 spike protein enhances viral infectivity and decreases neutralization sensitivity to individual convalescent sera. bioRxiv, https://doi.org/10.1101/2020.06.20.161323.

Huo, J., Zhao, Y., Ren, J., Zhou, D., Duyvesteyn, H.M.E., Ginn, H.M., Carrique, L., Malinauskas, T., Ruza, R.R., Shah, P.N.M., et al. (2020). Neutralization of SARS-CoV-2 by Destruction of the Prefusion Spike. Cell Host Microbe 28, 445-454.e6.

Ibarrondo, F.J., Fulcher, J.A., Goodman-Meza, D., Elliott, J., Hofmann, C., Hausner, M.A., Ferbas, K.G., Tobin, N.H., Aldrovandi, G.M., and Yang, O.O. (2020). Rapid decay of anti-SARS-CoV-2 antibodies in persons with mild COVID-19. N Engl J Med 383, 1085-1087.

Ibrahim, D., Dulipsingh, L., Zapatka, L., Eadie, R., Crowell, R., Williams, K., Wakefield, D.B., Cook, L., Puff, J., and Hussain, S.A. (2020). Factors associated with good patient outcomes following convalescent plasma in COVID-19: a prospective phase II clinical trial. Infect Dis Ther 9, 913-926.

Isho, B., Abe, K.T., Zuo, M., Jamal, A.J., Rathod, B., Wang, J.H., Li, Z., Chao, G., Rojas, O.L., Bang, Y.M., et al. (2020). Persistence of serum and saliva antibody responses to SARS-CoV-2 spike antigens in COVID-19 patients. Sci Immunol 5, abe5511.

Iyer, A.S., Jones, F.K., Nodoushani, A., Kelly, M., Becker, M., Slater, D.,
Mills, R., Teng, E., Kamruzzaman, M., Garcia-Beltran, W.F., et al. (2020). Persistence and decay of human antibody responses to the receptor binding domain of SARS-CoV-2 spike protein in COVID-19 patients. Sci Immunol 5, eabe0367.

Jackson, L.A., Anderson, E.J., Rouphael, N.G., Roberts, P.C., Makhene, M., Coler, R.N., McCullough, M.P., Chappell, J.D., Denison, M.R., Stevens, L.J., et al. (2020). An mRNA Vaccine against SARS-CoV-2 Preliminary Report. N Engl J Med 383, 1920-1931.

Jiang, S., Hillyer, C., and Du, L. (2020). Neutralizing antibodies against SARS-CoV-2 and other human coronaviruses. Trends Immunol 41, $355-359$

Jin, C., Gu, J., Yuan, Y., Long, Q., Zhang, Q., Zhou, H., Wu, W., and Zhang, W. (2020). Treatment of 6 COVID-19 Patients with Convalescent Plasma. medRxiv, https://doi.org/10.1016/j.ajpath.2020.05.014.

Johns Hopkins University. (2020). COVID-19 dashboard. https://coronavirus.jhu.edu/map.html.

Ju, B., Zhang, Q., Ge, J., Wang, R., Sun, J., Ge, X., Yu, J., Shan, S., Zhou, B., Song, S., et al. (2020). Human neutralizing antibodies elicited by SARS-CoV-2 infection. Nature 584, 115-119.

Juno, J.A., Tan, H.X., Lee, W.S., Reynaldi, A., Kelly, H.G., Wragg, K., Esterbauer, R., Kent, H.E., Batten, C.J., Mordant, F.L., et al. (2020). Humoral and circulating follicular helper $\mathrm{T}$ cell responses in recovered patients with COVID-19. Nat Med 26, 1428-1434.

Kapur, R., Della Valle, L., Sonneveld, M., Hipgrave Ederveen, A., Visser, R., Ligthart, P., de Haas, M., Wuhrer, M., van der Schoot, C.E., and Vidarsson, G. (2014). Low anti-RhD IgG-Fc-fucosylation in pregnancy: a new variable predicting severity in haemolytic disease of the fetus and newborn. Br J Haematol 166, 936-945.

Katzelnick, L.C., Gresh, L., Halloran, M.E., Mercado, J.C., Kuan, G., Gordon, A., Balmaseda, A., and Harris, E. (2017). Antibody-dependent enhancement of severe dengue disease in humans. Science 358, 929932.

Keith, P., Day, M., Choe, C., Perkins, L., Moyer, L., Hays, E., French, M., Hewitt, K., Gravel, G., Guffey, A., et al. (2020). The successful use of therapeutic plasma exchange for severe COVID-19 acute respiratory distress syndrome with multiple organ failure. SAGE Open Med Case Rep 8, $2050313 X 2093347$.

Kim, D., Lee, J.Y., Yang, J.S., Kim, J.W., Kim, V.N., and Chang, H. (2020). The architecture of SARS-CoV-2 transcriptome. Cell 181, 914-921.e10.

Korber, B., Fischer, W.M., Gnanakaran, S., Yoon, H., Theiler, J., Abfalterer, W., Hengartner, N., Giorgi, E.E., Bhattacharya, T., Foley, B., et al. (2020). Tracking changes in SARS-CoV-2 spike: Evidence that D614G increases infectivity of the COVID-19 virus. Cell 182, 812-827. e19.

Kutsuna, S., Asai, Y., and Matsunaga, A. (2020). Loss of Anti-SARS-CoV2 Antibodies in Mild Covid-19. N Engl J Med 383, 1695-1696.

Kuzmina, N.A., Younan, P., Gilchuk, P., Santos, R.I., Flyak, A.I., Ilinykh, P. A., Huang, K., Lubaki, N.M., Ramanathan, P., Crowe Jr., J.E., et al. (2018). Antibody-dependent enhancement of Ebola virus infection by human antibodies isolated from survivors. Cell Rep 24, 1802-1815.e5.

Lan, L., Xu, D., Ye, G., Xia, C., Wang, S., Li, Y., and Xu, H. (2020). Positive RT-PCR test results in patients recovered from COVID-19. JAMA 323, 1502.

Larsen, M.D., De Graaf, E.L., Sonneveld, M.E., Plomp, H.R., Linty, F., Visser, R., Brinkhaus, M., Sustic, T., De Taeye, S.W., Bentlage, A.E.H., et al. (2020). Afucosylated immunoglobulin $\mathrm{G}$ responses are a hallmark of enveloped virus infections and show an exacerbated phenotype in COVID-19. bioRxiv, https://doi.org/10.1101/2020.05.18.099507.

Lee, J.S., Kim, S.Y., Kim, T.S., Hong, K.H., Ryoo, N.H., Lee, J., Park, J.H., Cho, S.I., Kim, M.J., Kim, Y., et al. (2020a). Evidence of severe acute respiratory syndrome coronavirus 2 reinfection after recovery from mild coronavirus disease 2019. Clin Infect Dis, doi: 10.1093/cid/ciaa1421.

Lee, W.S., Wheatley, A.K., Kent, S.J., and DeKosky, B.J. (2020b). Antibody-dependent enhancement and SARS-CoV-2 vaccines and therapies. Nat Microbiol 5, 1185-1191.

Li, K., Wu, M., Huang, B., Zhong, A., Li, L., Cai, Y., Wu, L., Zhu, M., Li, 
J., Wang, Z., et al. (2020a). The dynamic changes of antibodies against SARS-CoV-2 during the infection and recovery of COVID-19. medRxiv, https://doi.org/10.1101/2020.05.18.20105155.

Li, L., Zhang, W., Hu, Y., Tong, X., Zheng, S., Yang, J., Kong, Y., Ren, L., Wei, Q., Mei, H., et al. (2020b). Effect of convalescent plasma therapy on time to clinical improvement in patients with severe and lifethreatening COVID-19. JAMA 324, 460.

Ling, R., Yu, Y., He, J., Zhang, J., Xu, S., Sun, R., Li, T., Ji, H., and Wang, H. (2020). Seroprevalence and epidemiological characteristics of immunoglobulin $\mathrm{M}$ and $\mathrm{G}$ antibodies against SARS-CoV-2 in asymptomatic people in Wuhan, China. medRxiv, https://doi.org/10.1101/ 2020.06.16.20132423.

Liu, L., Wei, Q., Lin, Q., Fang, J., Wang, H., Kwok, H., Tang, H., Nishiura, K., Peng, J., Tan, Z., et al. (2019). Anti-spike IgG causes severe acute lung injury by skewing macrophage responses during acute SARS-CoV infection. JCI Insight 4.

Liu, S.T.H., Lin, H.M., Baine, I., Wajnberg, A., Gumprecht, J.P., Rahman, F., Rodriguez, D., Tandon, P., Bassily-Marcus, A., Bander, J., et al. (2020a). Convalescent plasma treatment of severe COVID-19: a propensity score-matched control study. Nat Med 26, 1708-1713.

Liu, X., Gao, F., Gou, L., Chen, Y., Gu, Y., Ao, L., Shen, H., Hu, Z., Guo, X., and Gao, W. (2020b). Isolating multiple formats of human monoclonal neutralizing antibodies against SARS-CoV-2 by in vitro sitedirected antibody screening. bioRxiv, https://doi.org/10.1101/ 2020.05.03.074914

Liu, Z.L., Liu, Y., Wan, L.G., Xiang, T.X., Le, A.P., Liu, P., Peiris, M., Poon, L.L.M., and Zhang, W. (2020c). Antibody profiles in mild and severe cases of COVID-19. Clin Chem 66, 1102-1104.

Long, Q.X., Liu, B.Z., Deng, H.J., Wu, G.C., Deng, K., Chen, Y.K., Liao, P., Qiu, J.F., Lin, Y., Cai, X.F., et al. (2020a). Antibody responses to SARS-CoV-2 in patients with COVID-19. Nat Med 26, 845-848.

Long, Q.X., Tang, X.J., Shi, Q.L., Li, Q., Deng, H.J., Yuan, J., Hu, J.L., Xu, W., Zhang, Y., Lv, F.J., et al. (2020b). Clinical and immunological assessment of asymptomatic SARS-CoV-2 infections. Nat Med 26, $1200-1204$

Lou, B., Li, T.D., Zheng, S.F., Su, Y.Y., Li, Z.Y., Liu, W., Yu, F., Ge, S.X., Zou, Q.D., Yuan, Q., et al. (2020). Serology characteristics of SARSCoV-2 infection after exposure and post-symptom onset. Eur Respir J 56, 2000763.

Lu, L., Jiang, J., Zhan, M., Zhang, H., Wang, Q.T., Sun, S.N., Guo, X.K., Yin, H., Wei, Y., Li, S.Y., et al. (2020a). Targeting tumor-associated antigens in hepatocellular carcinoma for immunotherapy: past pitfalls and future strategies. Hepatology hep.31502.

Lu, L., Zhang, H., Zhan, M., Jiang, J., Yin, H., Dauphars, D.J., Li, S.Y., Li, Y., and He, Y.W. (2020b). Preventing mortality in COVID-19 patients: which cytokine to target in a raging storm? Front Cell Dev Biol 8.

Lu, R., Zhao, X., Li, J., Niu, P., Yang, B., Wu, H., Wang, W., Song, H., Huang, B., Zhu, N., et al. (2020c). Genomic characterisation and epidemiology of 2019 novel coronavirus: implications for virus origins and receptor binding. Lancet 395, 565-574.

Ludvigsson, J.F. (2020). Systematic review of COVID-19 in children shows milder cases and a better prognosis than adults. Acta Paediatr 109, 1088-1095.

Lv, Z., Deng, Y.Q., Ye, Q., Cao, L., Sun, C.Y., Fan, C., Huang, W., Sun, S., Sun, Y., Zhu, L., et al. (2020). Structural basis for neutralization of SARS-CoV-2 and SARS-CoV by a potent therapeutic antibody. Science $369,1505-1509$.

Lynch, K.L., Whitman, J.D., Lacanienta, N.P., Beckerdite, E.W., Kastner, S.A., Shy, B.R., Goldgof, G.M., Levine, A.G., Bapat, S.P., Stramer, S. L., et al. (2020). Magnitude and Kinetics of Anti-Severe Acute Respiratory Syndrome Coronavirus 2 Antibody Responses and Their Relationship to Disease Severity. Clin Infect Dis, doi: 10.1093/cid/ ciaa979.

Ma, H., Zhao, D., Zeng, W., Yang, Y., Hu, X., Zhou, P., Weng, J., Cheng, L., Zheng, X., and Jin, T. (2020). Decline of SARS-CoV-2-specific IgG, IgM and IgA in convalescent COVID-19 patients within 100 days after hospital discharge. Sci China Life Sci, doi: 10.1007/s11427-020-1805-
0.

Madariaga, M.L.L., Guthmiller, J.J., Schrantz, S., Jansen, M.O., Christensen, C., Kumar, M., Prochaska, M., Wool, G., DurkinCelauro, A., Oh, W.H., et al. (2020). Clinical predictors of donor antibody titre and correlation with recipient antibody response in a COVID-19 convalescent plasma clinical trial. J Intern Med joim.13185.

Maor, Y., Cohen, D., Paran, N., Israely, T., Ezra, V., Axelrod, O., Shinar, E., Izak, M., Rahav, G., Rahimi-Levene, N., et al. (2020). Compassionate use of convalescent plasma for treatment of moderate and severe pneumonia in COVID-19 patients and association with IgG antibody levels in donated plasma. EClinicalMedicine 26, 100525.

McGrath, J., Mcginty, T., Lynch, M., O'regan, E., Natin, D., O'gorman, P., and Lambert, J.S. (2020). COVID-19 relapse with prolonged viral shedding up to 60 days or re-infection, in 3 frontline healthcare workers with recurrent symptoms and persistent SARS-CoV-2 PCR positivity in Ireland, a developing diagnostic challenge: A case report. Research Square.

Mobini, M., Ghasemian, R., Larijani, L.V., Mataji, M., and Maleki, I. (2020). Vasculitis-associated auto-antibodies and complement levels in patients with COVID-19 infection. Research Square.

Mulligan, M.J., Lyke, K.E., Kitchin, N., Absalon, J., Gurtman, A., Lockhart, S., Neuzil, K., Raabe, V., Bailey, R., Swanson, K.A., et al. (2020). Phase I/II study of COVID-19 RNA vaccine BNT162b1 in adults. Nature 586, 589-593.

Ng, K.W., Faulkner, N., Cornish, G.H., Rosa, A., Harvey, R., Hussain, S., Ulferts, R., Earl, C., Wrobel, A.G., Benton, D.J., et al. (2020). Preexisting and de novo humoral immunity to SARS-CoV-2 in humans. Science eabe1107.

Ni, L., Ye, F., Cheng, M.L., Feng, Y., Deng, Y.Q., Zhao, H., Wei, P., Ge, J., Gou, M., Li, X., et al. (2020). Detection of SARS-CoV-2-specific humoral and cellular immunity in COVID-19 convalescent individuals. Immunity 52, 971-977.e3.

Noy-Porat, T., Makdasi, E., Alcalay, R., Mechaly, A., Levy, Y., BercovichKinori, A., Zauberman, A., Tamir, H., Yahalom-Ronen, Y., Israeli, M.'., et al. (2020). A panel of human neutralizing mAbs targeting SARSCoV-2 spike at multiple epitopes. Nat Commun 11, 4303.

Pei, S., Yuan, X., Zhang, Z., Yao, R., Xie, Y., Shen, M., Li, B., Chen, X., and Yin, M. (2020). Convalescent plasma to treat COVID-19: Chinese strategy and experiences. medRxiv, https://doi.org/10.1101/ 2020.04.07.20056440.

Peiris, J., Chu, C.M., Cheng, V., Chan, K.S., Hung, I., Poon, L., Law, K.I., Tang, B., Hon, T., Chan, C.S., et al. (2003). Clinical progression and viral load in a community outbreak of coronavirus-associated SARS pneumonia: a prospective study. Lancet 361, 1767-1772.

Percivalle, E., Cambiè, G., Cassaniti, I., Nepita, E.V., Maserati, R., Ferrari, A., Di Martino, R., Isernia, P., Mojoli, F., Bruno, R., et al. (2020). Prevalence of SARS-CoV-2 specific neutralising antibodies in blood donors from the Lodi Red Zone in Lombardy, Italy, as at 06 April 2020. Eurosurveillance 25.

Pereira, N.A., Chan, K.F., Lin, P.C., and Song, Z. (2018). The "less-ismore" in therapeutic antibodies: Afucosylated anti-cancer antibodies with enhanced antibody-dependent cellular cytotoxicity. mAbs 10, 693711.

Perotti, C., Baldanti, F., Bruno, R., Del Fante, C., Seminari, E., Casari, S., Percivalle, E., Glingani, C., Musella, V., Belliato, M., et al. (2020). Mortality reduction in 46 severe Covid-19 patients treated with hyperimmune plasma. A proof of concept single arm multicenter trial. Haematologica 105, 2834-2840.

Pierce, C.A., Preston-Hurlburt, P., Dai, Y., Aschner, C.B., Cheshenko, N., Galen, B., Garforth, S.J., Herrera, N.G., Jangra, R.K., Morano, N.C., et al. (2020). Immune responses to SARS-CoV-2 infection in hospitalized pediatric and adult patients. Sci Transl Med 12, eabd5487.

Pinto, D., Park, Y.J., Beltramello, M., Walls, A.C., Tortorici, M.A., Bianchi, S., Jaconi, S., Culap, K., Zatta, F., De Marco, A., et al. (2020). Crossneutralization of SARS-CoV-2 by a human monoclonal SARS-CoV antibody. Nature 583, 290-295.

Prado-Vivar, B., Becerra-Wong, M., Guadalupe, J.J., Márquez, S., 
Gutierrez, B., Rojas-Silva, P., Grunauer, M., Trueba, G., Barragán, V., and Cárdenas, P. (2020). A case of SARS-CoV-2 reinfection in Ecuador. Lancet Infect Dis, doi: 10.1016/S1473-3099(20)30910-5.

Prevost, J., Gasser, R., Beaudoin-Bussières, G., Richard, J., Duerr, R., Laumaea, A., Anand, S.P., Goyette, G., Benlarbi, M., Ding, S., et al. (2020). Cross-sectional evaluation of humoral responses against SARSCoV-2 spike. Cell Rep Med 1, 100126.

Radermecker, C., Detrembleur, N., Guiot, J., Cavalier, E., Henket, M., d'Emal, C., Vanwinge, C., Cataldo, D., Oury, C., Delvenne, P., et al. (2020). Neutrophil extracellular traps infiltrate the lung airway, interstitial, and vascular compartments in severe COVID-19. J Exp Med 217.

Ramasamy, M.N., Minassian, A.M., Ewer, K.J., Flaxman, A.L., Folegatti, P.M., Owens, D.R., Voysey, M., Aley, P.K., Angus, B., Babbage, G., et al. (2020). Safety and immunogenicity of ChAdOx1 nCoV-19 vaccine administered in a prime-boost regimen in young and old adults (COV002): a single-blind, randomised, controlled, phase $2 / 3$ trial. Lancet, doi: 10.1016/S0140-6736(20)32466-1.

Ren, L., Fan, G., Wu, W., Guo, L., Wang, Y., Li, X., Wang, C., Gu, X., Li, C., Wang, Y., et al. (2020). Antibody responses and clinical outcomes in adults hospitalized with severe coronavirus disease 2019 (COVID-19): A post hoc analysis of LOTUS China Trial. Clin Infect Dis, doi: 10.1093/cid/ciaa1247.

Robba, C., Battaglini, D., Pelosi, P., and Rocco, P.R.M. (2020). Multiple organ dysfunction in SARS-CoV-2: MODS-CoV-2. Expert Rev Respiratory Med 14, 865-868.

Robbiani, D.F., Gaebler, C., Muecksch, F., Lorenzi, J.C.C., Wang, Z., Cho, A., Agudelo, M., Barnes, C.O., Gazumyan, A., Finkin, S., et al. (2020). Convergent antibody responses to SARS-CoV-2 in convalescent individuals. Nature 584, 437-442.

Roeker, L.E., Knorr, D.A., Pessin, M.S., Ramanathan, L.V., Thompson, M. C., Leslie, L.A., Zelenetz, A.D., and Mato, A.R. (2020). Anti-SARS$\mathrm{CoV}-2$ antibody response in patients with chronic lymphocytic leukemia. Leukemia 34, 3047-3049.

Rogers, T.F., Zhao, F., Huang, D., Beutler, N., Burns, A., He, W., Limbo, O., Smith, C., Song, G., Woehl, J., et al. (2020). Isolation of potent SARS-CoV-2 neutralizing antibodies and protection from disease in a small animal model. Science eabc7520.

Sahin, U., Muik, A., Derhovanessian, E., Vogler, I., Kranz, L.M., Vormehr, M., Baum, A., Pascal, K., Quandt, J., Maurus, D., et al. (2020). COVID19 vaccine BNT162b1 elicits human antibody and TH1 T cell responses. Nature 586, 594-599.

Salazar, E., Kuchipudi, S.V., Christensen, P.A., Eagar, T., Yi, X., Zhao, P., Jin, Z., Long, S.W., Olsen, R.J., Chen, J., et al. (2020). Convalescent plasma anti-SARS-CoV-2 spike protein ectodomain and receptorbinding domain $\mathrm{IgG}$ correlate with virus neutralization. J Clin Invest 130, 6728-6738.

Sanyaolu, A., Okorie, C., Marinkovic, A., Prakash, S., Balendra, V., Desai, P., Abbasi, A.F., Haider, N., and Orish, V. (2020). Coronavirus disease19 and reinfections: a review of cases. Asclepius Medical Case Reports 3,5 .

Schoof, M., Faust, B., Saunders, R.A., Sangwan, S., Rezelj, V., Hoppe, N., Boone, M., Billesbølle, C.B., Puchades, C., Azumaya, C.M., et al. (2020). An ultrapotent synthetic nanobody neutralizes SARS-CoV-2 by stabilizing inactive Spike. Science eabe 3255 .

Selvaraj, V., Herman, K., and Dapaah-Afriyie, K. (2020). Severe, symptomatic reinfection in a patient with COVID-19. R I Med J (2013) 103 , 24-26.

Seydoux, E., Homad, L.J., MacCamy, A.J., Parks, K.R., Hurlburt, N.K., Jennewein, M.F., Akins, N.R., Stuart, A.B., Wan, Y.H., Feng, J., et al. (2020). Analysis of a SARS-CoV-2-infected individual reveals development of potent neutralizing antibodies with limited somatic mutation. Immunity 53, 98-105.e5.

Shao, Z., Feng, Y., Zhong, L., Xie, Q., Lei, M., Liu, Z., Wang, C., Ji, J., Liu, H., Gu, Z., et al. (2020). Clinical Efficacy of Intravenous Immunoglobulin Therapy in Critical Patients with COVID-19: A Multicenter Retrospective Cohort Study. medRxiv, http://dx.doi.org/10.2139/ ssrn. 3576827.

Shen, C., Wang, Z., Zhao, F., Yang, Y., Li, J., Yuan, J., Wang, F., Li, D., Yang, M., Xing, L., et al. (2020a). Treatment of 5 critically ill patients with COVID-19 with convalescent plasma. JAMA 323, 1582.

Shen, L., Wang, C., Zhao, J., Tang, X., Shen, Y., Lu, M., Ding, Z., Huang, C., Zhang, J., Li, S., et al. (2020b). Delayed specific IgM antibody responses observed among COVID-19 patients with severe progression. Emerg Microb Infect 9, 1096-1101.

Shi, R., Shan, C., Duan, X., Chen, Z., Liu, P., Song, J., Song, T., Bi, X., Han, C., Wu, L., et al. (2020). A human neutralizing antibody targets the receptor-binding site of SARS-CoV-2. Nature 584, 120-124.

Shields, R.L., Lai, J., Keck, R., O'Connell, L.Y., Hong, K., Meng, Y.G., Weikert, S.H.A., and Presta, L.G. (2002). Lack of fucose on human IgG1 $N$-linked oligosaccharide improves binding to human Fc $\gamma$ RIII and antibody-dependent cellular toxicity. J Biol Chem 277, 26733-26740.

Sun, Z., Chen, C., Li, W., Martinez, D.R., Drelich, A., Baek, D.S., Liu, X., Mellors, J.W., Tseng, C.T., Baric, R.S., et al. (2020). Potent neutralization of SARS-CoV-2 by human antibody heavy-chain variable domains isolated from a large library with a new stable scaffold. mAbs 12, 1778435.

Sung, J., and Anjum, S. (2020). Coronavirus disease 2019 (COVID-19) infection associated with antiphospholipid antibodies and fourextremity deep vein thrombosis in a previously healthy female. Cureus, doi: 10.7759/cureus.8408.

Sungnak, W., Huang, N., Bécavin, C., Berg, M., Queen, R., Litvinukova, M., Talavera-López, C., Maatz, H., Reichart, D., Sampaziotis, F., et al. (2020). SARS-CoV-2 entry factors are highly expressed in nasal epithelial cells together with innate immune genes. Nat Med 26, 681687.

Tai, W., Zhang, X., He, Y., Jiang, S., and Du, L. (2020). Identification of SARS-CoV RBD-targeting monoclonal antibodies with cross-reactive or neutralizing activity against SARS-CoV-2. Antiviral Res 179, 104820.

Terpos, E., Mentis, A., and Dimopoulos, M.A. (2020). Loss of anti-SARSCoV-2 antibodies in mild COVID-19. N Engl J Med 383, 1695.

Tetro, J.A. (2020). Is COVID-19 receiving ADE from other coronaviruses? Microb Infect 22, 72-73.

Thomas, S.N., Altawallbeh, G., Zaun, C., Pape, K., Peters, J.M., Titcombe, P.J., Dileepan, T., Rapp, M.J., Bold, T.D., Schacker, T., et al. (2020). Initial determination of COVID-19 seroprevalence among outpatients and healthcare workers in Minnesota using a novel SARS-CoV-2 total antibody ELISA. SSRN, https://doi.org/10.2139/ssrn.3627313.

Tian, X., Li, C., Huang, A., Xia, S., Lu, S., Shi, Z., Lu, L., Jiang, S., Yang, Z., Wu, Y., et al. (2020). Potent binding of 2019 novel coronavirus spike protein by a SARS coronavirus-specific human monoclonal antibody. Emerg Microb Infect 9, 382-385.

Tillett, R.L., Sevinsky, J.R., Hartley, P.D., Kerwin, H., Crawford, N., Gorzalski, A., Laverdure, C., Verma, S.C., Rossetto, C.C., Jackson, D., et al. (2020). Genomic evidence for reinfection with SARS-CoV-2: a case study. Lancet Infect Dis, doi: 10.1016/S1473-3099(20)30764-7.

To, K.K.W., Hung, I.F.N., Ip, J.D., Chu, A.W.H., Chan, W.M., Tam, A.R., Fong, C.H.Y., Yuan, S., Tsoi, H.W., Ng, A.C.K., et al. (2020a). Coronavirus disease 2019 (COVID-19) re-infection by a phylogenetically distinct severe acute respiratory syndrome coronavirus 2 strain confirmed by whole genome sequencing. Clin Infect Dis, doi: 10.1093/cid/ciaa1275.

To, K.K.W., Tsang, O.T.Y., Leung, W.S., Tam, A.R., Wu, T.C., Lung, D.C., Yip, C.C.Y., Cai, J.P., Chan, J.M.C., Chik, T.S.H., et al. (2020b). Temporal profiles of viral load in posterior oropharyngeal saliva samples and serum antibody responses during infection by SARS-CoV2: an observational cohort study. Lancet Infect Dis 20, 565-574.

Torres, D.A., Ribeiro, L.C.B., Riello, A.P.F.L., Horovitz, D.D.G., Pinto, L. F.R., and Croda, J. (2020). Reinfection of COVID-19 after 3 months with a distinct and more aggressive clinical presentation: Case report. J Med Virol jmv.26637.

Tortorici, M.A., Beltramello, M., Lempp, F.A., Pinto, D., Dang, H.V., Rosen, L.E., McCallum, M., Bowen, J., Minola, A., Jaconi, S., et al. 
(2020). Ultrapotent human antibodies protect against SARS-CoV-2 challenge via multiple mechanisms. Science 370, 950-957.

Tse, L.V., Meganck, R.M., Graham, R.L., and Baric, R.S. (2020). The current and future state of vaccines, antivirals and gene therapies against emerging coronaviruses. Front Microbiol 11, 658.

Tseng, C.T., Sbrana, E., Iwata-Yoshikawa, N., Newman, P.C., Garron, T., Atmar, R.L., Peters, C.J., and Couch, R.B. (2012). Immunization with SARS coronavirus vaccines leads to pulmonary immunopathology on challenge with the SARS virus. PLoS ONE 7, e35421.

Uyoga, S., Adetifa, I.M.O., Karanja, H.K., Nyagwange, J., Tuju, J., Wanjiku, P., Aman, R., Mwangangi, M., Amoth, P., Kasera, K., et al. (2020). Seroprevalence of anti-SARS-CoV-2 IgG antibodies in Kenyan blood donors. Science eabe1916.

Vlachoyiannopoulos, P.G., Magira, E., Alexopoulos, H., Jahaj, E., Theophilopoulou, K., Kotanidou, A., and Tzioufas, A.G. (2020). Autoantibodies related to systemic autoimmune rheumatic diseases in severely ill patients with COVID-19. Ann Rheum Dis 79, 1661-1663.

Wajnberg, A., Amanat, F., Firpo, A., Altman, D.R., Bailey, M.J., Mansour, M., McMahon, M., Meade, P., Mendu, D.R., Muellers, K., et al. (2020). Robust neutralizing antibodies to SARS-CoV-2 infection persist for months. Science eabd7728.

Walsh, E.E., Frenck Jr., R.W., Falsey, A.R., Kitchin, N., Absalon, J., Gurtman, A., Lockhart, S., Neuzil, K., Mulligan, M.J., Bailey, R., et al. (2020). Safety and immunogenicity of two RNA-based COVID-19 vaccine candidates. N Engl J Med NEJMoa2027906.

Wan, J., Xing, S., Ding, L., Wang, Y., Gu, C., Wu, Y., Rong, B., Li, C., Wang, S., Chen, K., et al. (2020a). Human-IgG-neutralizing monoclonal antibodies block the SARS-CoV-2 infection. Cell Rep 32, 107918.

Wan, Y., Shang, J., Sun, S., Tai, W., Chen, J., Geng, Q., He, L., Chen, Y., Wu, J., Shi, Z., et al. (2020b). Molecular mechanism for antibodydependent enhancement of coronavirus entry. J Virol 94.

Wang, C., Li, W., Drabek, D., Okba, N.M.A., van Haperen, R., Osterhaus, A.D.M.E., van Kuppeveld, F.J.M., Haagmans, B.L., Grosveld, F., and Bosch, B.J. (2020a). A human monoclonal antibody blocking SARSCoV-2 infection. Nat Commun 11, 2251.

Wang, K., Chen, W., Zhou, Y.S., Lian, J.Q., Zhang, Z., Du, P., Gong, L., Zhang, Y., Cui, H.Y., Geng, J.J., et al. (2020b). SARS-CoV-2 invades host cells via a novel route: CD147-spike protein. bioRxiv, https://doi. org/10.1101/2020.03.14.988345.

Wang, M., Yang, X., Yang, F., Zhu, X., Sun, Z., Bao, P., and Yan, Y. (2020c). Convalescent plasma therapy in critically ill coronavirus disease 2019 patients with persistently positive nucleic acid test, case series report. Medicine 99, e21596.

Wang, Q., Zhang, L., Kuwahara, K., Li, L., Liu, Z., Li, T., Zhu, H., Liu, J., $\mathrm{Xu}, \mathrm{Y}$., Xie, J., et al. (2016). Immunodominant SARS coronavirus epitopes in humans elicited both enhancing and neutralizing effects on infection in non-human primates. ACS Infect Dis 2, 361-376.

Wang, Q., Zhang, Y., Wu, L., Niu, S., Song, C., Zhang, Z., Lu, G., Qiao, C., $\mathrm{Hu}$, Y., Yuen, K.Y., et al. (2020d). Structural and functional basis of SARS-CoV-2 entry by using human ACE2. Cell 181, 894-904.e9.

Wang, S.F., Tseng, S.P., Yen, C.H., Yang, J.Y., Tsao, C.H., Shen, C.W., Chen, K.H., Liu, F.T., Liu, W.T., Chen, Y.M.A., et al. (2014). Antibodydependent SARS coronavirus infection is mediated by antibodies against spike proteins. Biochem Biophys Res Commun 451, 208-214.

Wang, X., Guo, X., Xin, Q., Pan, Y., Hu, Y., Li, J., Chu, Y., Feng, Y., and Wang, Q. (2020e). Neutralizing antibody responses to severe acute respiratory syndrome coronavirus 2 in coronavirus disease 2019 inpatients and convalescent patients. Clin Infect Dis, doi: 10.1093/cid/ ciaa721.

Wec, A.Z., Wrapp, D., Herbert, A.S., Maurer, D.P., Haslwanter, D., Sakharkar, M., Jangra, R.K., Dieterle, M.E., Lilov, A., Huang, D., et al. (2020). Broad neutralization of SARS-related viruses by human monoclonal antibodies. Science 369, 731-736.

Weingartl, H., Czub, M., Czub, S., Neufeld, J., Marszal, P., Gren, J., Smith, G., Jones, S., Proulx, R., Deschambault, Y., et al. (2004). Immunization with modified vaccinia virus Ankara-based recombinant vaccine against severe acute respiratory syndrome is associated with enhanced hepatitis in ferrets. J Virol 78, 12672-12676.

Weisberg, S.P., Connors, T.J., Zhu, Y., Baldwin, M.R., Lin, W.H., Wontakal, S., Szabo, P.A., Wells, S.B., Dogra, P., Gray, J., et al. (2020). Distinct antibody responses to SARS-CoV-2 in children and adults across the COVID-19 clinical spectrum. Nat Immunol, doi: 10.1038/s41590-020-00826-9.

Woodruff, M.C., Ramonell, R.P., Cashman, K.S., Nguyen, D.C., Ley, A.M., Kyu, S., Saini, A., Haddad, N., Chen, W., Howell, J.C., et al. (2020). Critically ill SARS-CoV-2 patients display lupus-like hallmarks of extrafollicular B cell activation. medRxiv, https://oi.org/10.1101/ 2020.04.29.20083717.

Wu, F., Liu, M., Wang, A., Lu, L., Wang, Q., Gu, C., Chen, J., Wu, Y., Xia, S., Ling, Y., et al. (2020a). Evaluating the association of clinical characteristics with neutralizing antibody levels in patients who have recovered from mild COVID-19 in Shanghai, China. JAMA Intern Med $180,1356-1362$.

Wu, Y., Li, C., Xia, S., Tian, X., Kong, Y., Wang, Z., Gu, C., Zhang, R., Tu, C., Xie, Y., et al. (2020b). Identification of human single-domain antibodies against SARS-CoV-2. Cell Host Microbe 27, 891-898.e5.

Wu, Y., Wang, F., Shen, C., Peng, W., Li, D., Zhao, C., Li, Z., Li, S., Bi, Y., Yang, Y., et al. (2020c). A noncompeting pair of human neutralizing antibodies block COVID-19 virus binding to its receptor ACE2. Science 368, 1274-1278.

Xia, S., Duan, K., Zhang, Y., Zhao, D., Zhang, H., Xie, Z., Li, X., Peng, C., Zhang, Y., Zhang, W., et al. (2020a). Effect of an inactivated vaccine against SARS-CoV-2 on safety and immunogenicity outcomes. JAMA 324, 951-960.

Xia, Z., Liu, X., Hu, X., Zhong, Z., Wang, Y., Peng, G., and Ye, Q. (2020b). Failed antibody response in a renal transplant recipient with SARSCoV-2 infected. Transpl Infect Dis 22.

Xiang, Y., Nambulli, S., Xiao, Z., Liu, H., Sang, Z., Duprex, W.P., Schneidman-Duhovny, D., Zhang, C., and Shi, Y. (2020). Versatile and multivalent nanobodies efficiently neutralize SARS-CoV-2. Science eabe4747.

Xu, X., Sun, J., Nie, S., Li, H., Kong, Y., Liang, M., Hou, J., Huang, X., Li, D., Ma, T., et al. (2020). Seroprevalence of immunoglobulin M and G antibodies against SARS-CoV-2 in China. Nat Med 26, 1193-1195.

Yahalom-Ronen, Y., Tamir, H., Melamed, S., Politi, B., Shifman, O., Achdout, H., Vitner, E.B., Israeli, O., Milrot, E., Stein, D., et al. (2020). A single dose of recombinant VSV- G-spike vaccine provides protection against SARS-CoV-2 challenge. bioRxiv, https://oi.org/10.1101/ 2020.06.18.160655.

Yan, R., Zhang, Y., Li, Y., Xia, L., Guo, Y., and Zhou, Q. (2020). Structural basis for the recognition of SARS-CoV-2 by full-length human ACE2. Science 367, 1444-1448.

Yang, X., Yu, Y., Xu, J., Shu, H., Xia, J., Liu, H., Wu, Y., Zhang, L., Yu, Z., Fang, M., et al. (2020). Clinical course and outcomes of critically ill patients with SARS-CoV-2 pneumonia in Wuhan, China: a singlecentered, retrospective, observational study. Lancet Respir Med 8, 475481.

Ye, M., Fu, D., Ren, Y., Wang, F., Wang, D., Zhang, F., Xia, X., and Lv, T. (2020a). Treatment with convalescent plasma for COVID-19 patients in Wuhan, China. J Med Virol 92, 1890-1901.

Ye, X., Xiao, X., Li, B., Zhu, W., Li, Y., Wu, J., Huang, X., Jin, J., Chen, D., Jin, J., et al. (2020b). Low humoral immune response and ineffective clearance of SARS-Cov-2 in a COVID-19 patient with CLL during a 69-day follow-up. Front Oncol 10, 1272.

Yu, H., Sun, B., Fang, Z., Zhao, J., Liu, X., Li, Y., Sun, X., Liang, H., Zhong, B., Huang, Z., et al. (2020a). Distinct features of SARS-CoV-2specific IgA response in COVID-19 patients. Eur Respir J 56, 2001526.

Yu, J., Tostanoski, L.H., Peter, L., Mercado, N.B., McMahan, K., Mahrokhian, S.H., Nkolola, J.P., Liu, J., Li, Z., Chandrashekar, A., et al. (2020b). DNA vaccine protection against SARS-CoV-2 in rhesus macaques. Science 369, 806-811.

Yuan, A.Q., Zhao, L., Bai, L., Meng, Q., Wen, Z., Li, Y., Guo, D., Zhen, S., Chen, X., Yang, J., et al. (2020a). Isolation of and characterization of neutralizing antibodies to COVID-19 from a large human naive $\mathrm{scFv}$ 
phage display library bioRxiv, https://doi.org/10.1101/ 2020.05.19.104281.

Yuan, M., Wu, N.C., Zhu, X., Lee, C.C.D., So, R.T.Y., Lv, H., Mok, C.K.P., and Wilson, I.A. (2020b). A highly conserved cryptic epitope in the receptor binding domains of SARS-CoV-2 and SARS-CoV. Science $368,630-633$.

Yurkovetskiy, L., Wang, X., Pascal, K.E., Tomkins-Tinch, C., Nyalile, T.P., Wang, Y., Baum, A., Diehl, W.E., Dauphin, A., Carbone, C., et al. (2020). Structural and functional analysis of the D614G SARS-CoV-2 spike protein variant. Cell 183, 739-751.e8.

Zeng, X., Li, L., Lin, J., Li, X., Liu, B., Kong, Y., Zeng, S., Du, J., Xiao, H., Zhang, T., et al. (2020). Isolation of a human monoclonal antibody specific for the receptor binding domain of SARS-CoV-2 using a competitive phage biopanning strategy. Antibody Therapeutics 3, 95100.

Zhang, B., Liu, S., Tan, T., Huang, W., Dong, Y., Chen, L., Chen, Q., Zhang, L., Zhong, Q., Zhang, X., et al. (2020a). Treatment with convalescent plasma for critically ill patients with severe acute respiratory syndrome coronavirus 2 infection. Chest 158, e9-e13.

Zhang, F., Gan, R., Zhen, Z., Hu, X., Li, X., Zhou, F., Liu, Y., Chen, C., Xie, S., Zhang, B., et al. (2020b). Adaptive immune responses to SARSCoV-2 infection in severe versus mild individuals. Sig Transduct Target Ther 5, 156.

Zhang, G., Nie, S., Zhang, Z., and Zhang, Z. (2020c). Longitudinal Change of Severe Acute Respiratory Syndrome Coronavirus 2 Antibodies in Patients with Coronavirus Disease 2019. J Infect Dis 222, 183-188.

Zhang, J., Zeng, H., Gu, J., Li, H., Zheng, L., and Zou, Q. (2020d). Progress and prospects on vaccine development against SARS-CoV-2. Vaccines 8, 153 .

Zhang, L., Jackson, C.B., Mou, H., Ojha, A., Rangarajan, E.S., Izard, T., Farzan, M., and Choe, H. (2020e). The D614G mutation in the SARS$\mathrm{CoV}-2$ spike protein reduces $\mathrm{S} 1$ shedding and increases infectivity. bioRxiv, https://doi.org/10.1101/2020.06.12.148726.

Zhang, Y., Xiao, M., Zhang, S., Xia, P., Cao, W., Jiang, W., Chen, H., Ding, X., Zhao, H., Zhang, H., et al. (2020f). Coagulopathy and antiphospholipid antibodies in patients with COVID-19. N Engl J Med 382, e38.

Zhang, Y., Zeng, G., Pan, H., Li, C., Hu, Y., Chu, K., Han, W., Chen, Z., Tang, R., Yin, W., et al. (2020g). Safety, tolerability, and immunogenicity of an inactivated SARS-CoV-2 vaccine in healthy adults aged 18-59 years: a randomised, double-blind, placebo- controlled, phase 1/2 clinical trial. Lancet Infect Dis, doi: 10.1016/ S1473-3099(20)30843-4.

Zhao, J., Yuan, Q., Wang, H., Liu, W., Liao, X., Su, Y., Wang, X., Yuan, J., $\mathrm{Li}, \mathrm{T}$., Li, J., et al. (2020). Antibody responses to SARS-CoV-2 in patients with novel coronavirus disease 2019. Clin Infect Dis, doi: 10.1093/cid/ciaa344.

Zhou, F., Yu, T., Du, R., Fan, G., Liu, Y., Liu, Z., Xiang, J., Wang, Y., Song, B., Gu, X., et al. (2020a). Clinical course and risk factors for mortality of adult inpatients with COVID-19 in Wuhan, China: a retrospective cohort study. Lancet 395, 1054-1062.

Zhou, P., Yang, X.L., Wang, X.G., Hu, B., Zhang, L., Zhang, W., Si, H.R., Zhu, Y., Li, B., Huang, C.L., et al. (2020b). A pneumonia outbreak associated with a new coronavirus of probable bat origin. Nature 579, 270-273.

Zhu, F.C., Guan, X.H., Li, Y.H., Huang, J.Y., Jiang, T., Hou, L.H., Li, J.X., Yang, B.F., Wang, L., Wang, W.J., et al. (2020a). Immunogenicity and safety of a recombinant adenovirus type-5-vectored COVID-19 vaccine in healthy adults aged 18 years or older: a randomised, double-blind, placebo-controlled, phase 2 trial. Lancet 396, 479-488.

Zhu, F.C., Li, Y.H., Guan, X.H., Hou, L.H., Wang, W.J., Li, J.X., Wu, S.P., Wang, B.S., Wang, Z., Wang, L., et al. (2020b). Safety, tolerability, and immunogenicity of a recombinant adenovirus type- 5 vectored COVID19 vaccine: a dose-escalation, open-label, non-randomised, first-inhuman trial. Lancet 395, 1845-1854.

Zhu, Y., Yu, D., Han, Y., Yan, H., Chong, H., Ren, L., Wang, J., Li, T., and He, Y. (2020c). Cross-reactive neutralization of SARS-CoV-2 by serum antibodies from recovered SARS patients and immunized animals. Sci Adv 6, eabc9999.

Zohar, T., Loos, C., Fischinger, S., Atyeo, C., Wang, C., Slein, M.D., Burke, J., Yu, J., Feldman, J., Hauser, B.M., et al. (2020). Compromised humoral functional evolution tracks with SARS-CoV-2 mortality. Cell, doi: 10.1016/j.cell.2020.10.052.

Zost, S.J., Gilchuk, P., Chen, R.E., Case, J.B., Reidy, J.X., Trivette, A., Nargi, R.S., Sutton, R.E., Suryadevara, N., Chen, E.C., et al. (2020). Rapid isolation and profiling of a diverse panel of human monoclonal antibodies targeting the SARS-CoV-2 spike protein. Nat Med 26, 14221427.

Zuo, Y., Estes, S.K., Ali, R.A., Gandhi, A.A., Yalavarthi, S., Shi, H., Sule, G., Gockman, K., Madison, J.A., Zuo, M., et al. (2020). Prothrombotic autoantibodies in serum from patients hospitalized with COVID-19. Sci Transl Med 12, eabd3876. 